\title{
Molecular functions of nitric oxide and its potential applications in horticultural crops
}

\author{
Chengliang Sun ${ }^{1}$, Yuxue Zhang ${ }^{1}$, Lijuan Liư², Xiaoxia Liư ${ }^{3}$, Baohai Li ${ }^{1}$ Chongwei Jin ${ }^{1}$ and Xianyong Lin ${ }^{1}$
}

\begin{abstract}
Nitric oxide (NO) regulates plant growth, enhances nutrient uptake, and activates disease and stress tolerance mechanisms in most plants, making $\mathrm{NO}$ a potential tool for use in improving the yield and quality of horticultural crop species. Although the use of $\mathrm{NO}$ in horticulture is still in its infancy, research on NO in model plant species has provided an abundance of valuable information on horticultural crop species. Emerging evidence implies that the bioactivity of $\mathrm{NO}$ can occur through many potential mechanisms but occurs mainly through S-nitrosation, the covalent and reversible attachment of NO to cysteine thiol. In this context, NO signaling specifically affects crop development, immunity, and environmental interactions. Moreover, $\mathrm{NO}$ can act as a fumigant against a wide range of postharvest diseases and pests. However, for effective use of NO in horticulture, both understanding and exploring the biological significance and potential mechanisms of $\mathrm{NO}$ in horticultural crop species are critical. This review provides a picture of our current understanding of how NO is synthesized and transduced in plants, and particular attention is given to the significance of $\mathrm{NO}$ in breaking seed dormancy, balancing root growth and development, enhancing nutrient acquisition, mediating stress responses, and guaranteeing food safety for horticultural production.
\end{abstract}

\section{Introduction}

Nitric oxide (NO) is a redox-active molecule that orchestrates a myriad of physiological and biochemical functions in biological organisms ${ }^{1-3}$. NO has been particularly well studied in mammals, where it regulates physiological processes of vital importance, such as neurotransmission and immunological and inflammatory responses $^{3-6}$. Due to the active research and great achievements of $\mathrm{NO}$ in relation to human health issues, NO was named "Molecule of the Year" in 1992 by the journal Science and was the subject of the Nobel Prize for Physiology and Medicine in 1998. Despite the considerable amounts of attention this gaseous free radical has garnered within animal systems, the first identification of NO formation in biological systems occurred in plants ${ }^{7}$.

\footnotetext{
Correspondence: Xianyong Lin (xylin@zju.edu.cn)

${ }^{1} \mathrm{MOE}$ Key Laboratory of Environment Remediation and Ecological Health,

College of Environmental \& Resource Sciences, Zhejiang University, 310058 Hangzhou, China

${ }^{2}$ Interdisciplinary Research Academy, Zhejiang Shuren University, 310015 Hangzhou, China

Full list of author information is available at the end of the article
}

Since then, the sources, signaling, molecular mechanisms, functions, and targets of NO have been thoroughly investigated in plants during the past few decades ${ }^{1,8-12}$.

The biological function of NO was first reported to be associated with plant immunity responses, initially in potato (Solarium tuberosum) $)^{13}$ and then in tobacco (Nicotiana tabacum $)^{14}$, soybean (Glycine max $)^{15}$, and Arabidopsis (Arabidopsis thaliana) ${ }^{8}$. These findings cemented NO as a crucial messenger in plant-pathogen interactions. Since then, many additional functions have been discovered (Fig. 1). NO regulates a variety of processes integral to plant growth and development, such as seed germination, root development, flower transition, and fruit ripening, as well as plant responses and adaptations to unfavorable environmental conditions ${ }^{9,12,16-21}$. Further, the complementary use of new tools and biological technologies have allowed the characterization of its biosynthesis routes and mode of action in plants.

Horticultural crops are an important component of agriculture for food as well as for nutritional security. The improvement in the growth, yield, and quality of

\section{(c) The Author(s) 2021}

(c) Open Access This article is licensed under a Creative Commons Attribution 4.0 International License, which permits use, sharing, adaptation, distribution and reproduction cc) in any medium or format, as long as you give appropriate credit to the original author(s) and the source, provide a link to the Creative Commons license, and indicate if changes were made. The images or other third party material in this article are included in the article's Creative Commons license, unless indicated otherwise in a credit line to the material. If material is not included in the article's Creative Commons license and your intended use is not permitted by statutory regulation or exceeds the permitted use, you will need to obtain permission directly from the copyright holder. To view a copy of this license, visit http://creativecommons.org/licenses/by/4.0/. 


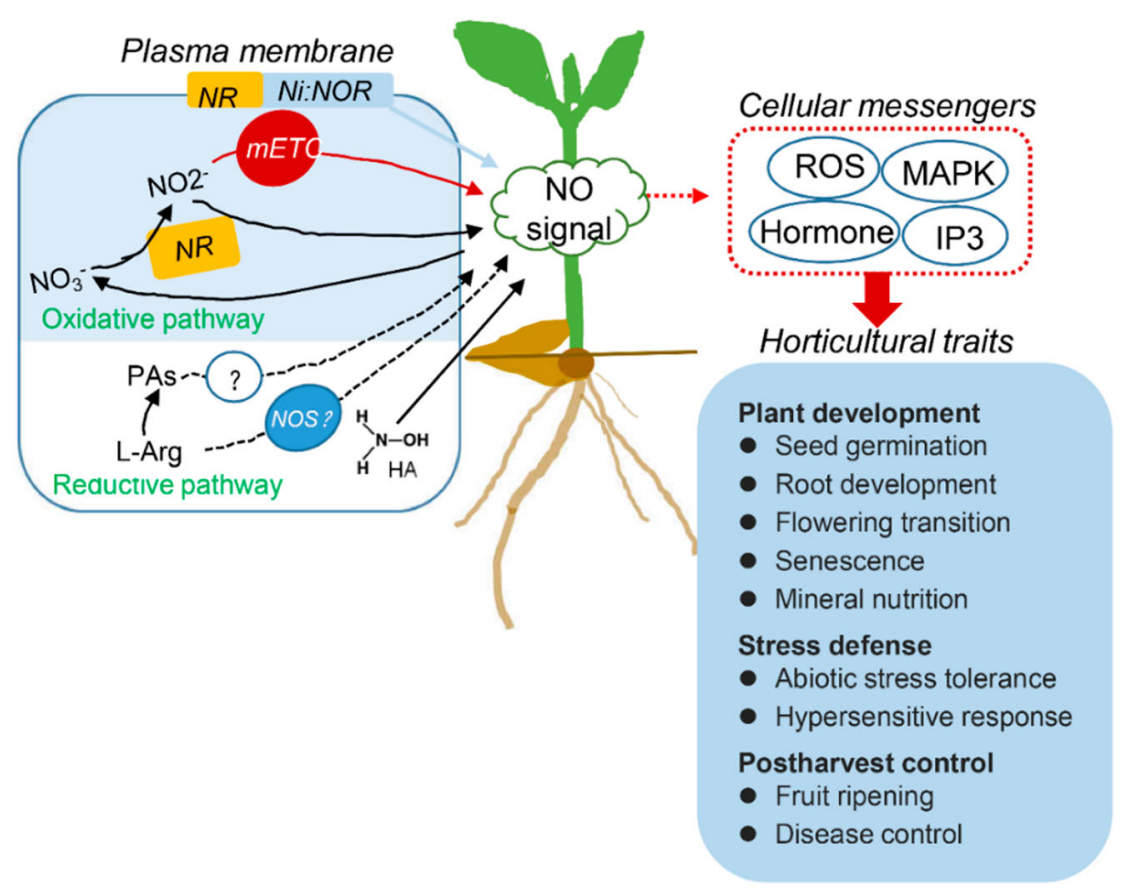

Fig. 1 Sources of NO production and NO functions in regulating plant growth, development, and adaptive processes. The reductive pathway is based on the reduction of nitrite to NO, whereas the oxidative route relies on the oxidation of aminated molecules, such as L-Arg. The produced $\mathrm{NO}$ can be used to transduce external and internal signals to regulate plant development and stress responses by interacting with other cellular messengers. NR, nitrate reductase; Ni:NOR, NO-forming nitrite reductase; mETC, mitochondrial nitrite reduction; NOS, nitric oxide synthase; L-Arg, L-arginine; PA, polyamine; HA, hydroxylamine

horticultural crops has received a large amount of attention in recent years. Given the unique properties associated with plant growth and development, research on $\mathrm{NO}$ in horticultural crop species is substantially increasing ${ }^{22-27}$. The various roles of $\mathrm{NO}$ in plant biology make $\mathrm{NO}$ signaling a promising target for stimulating seed germination, optimizing root architecture, promoting plant growth and development, enhancing mineral nutrient acquisition, delaying postharvest fruit senescence, and increasing resistance to biotic and abiotic stresses. Moreover, with the advancement of genome-editing technologies, genetic manipulation of NO action in horticultural crops might have practical and promising prospects in the future.

\section{Current understanding of NO biosynthesis and bioactivity NO biosynthesis}

Extensive research in different plant species and in various biological situations has revealed the coexistence of multiple routes with likely functions in plants, which depend on either reductive or oxidative mechanisms $^{9,11,28,29}$. The reductive pathway is based on the reduction of nitrite to $\mathrm{NO}$, whereas the oxidative route relies on the oxidation of aminated molecules (Fig. 1). However, significant controversy regarding our current understanding of $\mathrm{NO}$ biosynthesis in plant cells remains.
Reductive pathways are dependent upon nitrite as the primary substrate, which can be catalyzed by nitrate reductase (NR), NO-forming nitrite reductase (NOFNiR), and mitochondrial nitrite reduction ${ }^{9,28,30,31}$. Among these routes, NR-mediated NO generation from nitrite has been assumed to be the main enzymatic source in plants ${ }^{32,33}$. Since the early 2000s, a large number of independent studies have indicated a role for NR in the formation of NO integral to a variety of processes, including stomatal movement, the floral transition, auxin-regulated lateral root formation, root hair development, and various stress defense responses ${ }^{18,34-37}$. It should be noted that NR primarily catalyzes the reduction of nitrate to nitrite, and nitrite reduction constitutes only $1 \%$ of NR activity ${ }^{30}$, indicating extremely low levels of NO production resulting from this route under normal conditions. However, under acidic conditions or under high concentrations of nitrite and low nitrate, NR-dependent NO emission is accelerated in plant cells. Subsequent work showed that posttranslational regulation of NR via the phosphorylation of a conserved serine residue enables NR to bind to 14-3-3 proteins, leading to NR inactivation and degradation ${ }^{38}$. In addition to $\mathrm{NR}$, the participation of a plasma membrane-bound nitrite reductase (Ni:NOR) in the germination of $\mathrm{NO}$ was first reported in tobacco ${ }^{39}$, with activity being limited in the roots. In conjunction with an apoplastic membrane-bound 
$\mathrm{NR}, \mathrm{Ni}$ :NOR produces $\mathrm{NO}$ in the apoplast and plays pivotal roles in sensing nitrate availability and regulating mycorrhizal colonization ${ }^{40,41}$. Although NOFNiR has been suggested to be a component of another NO-producing route from nitrites, the functionality of this system has been detected only in Chlamydomonas reinhardtii ${ }^{42}$ and remains largely unknown in higher plants. Like NR and NOFNiR, other enzymes such as xanthine oxidase containing a molybdenum cofactor in their structure show the potential to produce NO from nitrite in plants ${ }^{43}$. At present, however, no information is available on their NO synthesis ability in plants. Other proposed reductive routes for NO production include the mitochondrial electron transport chain (mETC), as mETC inhibitors prevent NO biosynthesis in algae and tobacco ${ }^{44,45}$.

Regarding the oxidative pathway contributing to NO production, several lines of evidence demonstrate that plants are able to synthesize $\mathrm{NO}$ by oxidizing $\mathrm{N}$ containing molecules, similar to the dominant pathway in animals. The oxidation of arginine to citrulline and NO, which is catalyzed by three distinct nitric oxide synthases (NOSs) in mammals, has also been proposed to occur in higher plants ${ }^{46,47}$. Several studies have sought to identify and characterize NOS homologs in the plant kingdom. A candidate, initially named AtNOS1, was identified in Arabidopsis based on its similarity with a protein involved in NO generation in the snail Helix pomatia ${ }^{48}$. However, researchers subsequently characterized it as a functional small GTPase and therefore renamed nitric oxide associated 1 (AtNOA 1$)^{49}$. In the beginning of 2010 , a related protein with $45 \%$ sequence similarity to the human eNOS sequence was identified in the green alga Ostreococcus tauri $^{50}$. However, a systematic search for homologous human nNOS sequences in more than 1000 land plants and algae showed that 15 typically identified NOSs belonged to algal species, whereas no NOS homologs were found in the genomes of land plants ${ }^{51}$. These findings and previously unsuccessful attempts to identify candidates suggest that canonical NOSs might not exist in higher plants. According to phylogenic relationships, NOS was later lost in land plants. However, it cannot be excluded that some key motifs or single residues important for NOS activity are conserved; thus, animal NOS inhibitors also function in plants. It has been proposed that hydroxylamine-mediated NO synthesis constitutes another potential oxidative rout $\mathrm{e}^{52}$, and $\mathrm{NO}$ produced in this way is considered to participate in regulating seed germination and tolerance to abiotic stresses, such as salt, oxidative and drought stresses. However, the subcellular location and level of hydroxylamine-mediated NO currently are unknown. Several works have reported that increased levels of polyamines such as spermine and spermidine resulted in NO release in several plant spe$\operatorname{cies}^{53}$. Although the underlying mechanism has not yet been resolved, polyamine-induced NO has been suggested to regulate root development and embryogenesis as well as plant responses to cadmium and drought stress ${ }^{54}$.

\section{Transfer of NO bioactivity}

The molecular details underpinning exactly how $\mathrm{NO}$ as a signaling messenger is translated into biological function have been under extensive research in recent decades. In animals, NOS-mediated NO is perceived by soluble guanylate cyclase through binding to prosthetic hemes, leading to the production of cyclic $3^{\prime}, 5^{\prime}$-guanosine monophosphate $(\mathrm{cGMP})^{2,55}$. Although low levels of cGMP have been detected in plants, a NO-cGMP signaling pathway, however, might not exist in plants according to recent bioinformatic analyses in over 1000 plant species ${ }^{51}$. In the absence of an NO receptor, NO likely conveys its bioactivity through chemical interactions with specific residues of target proteins that undergo NO-dependent post-

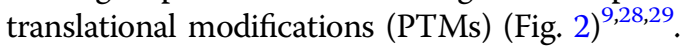

Among these PTMs, S-nitrosation is key, which describes the covalent and reversible attachment of NO to a reactive thiol group of cysteine forming an $S$-nitosothiol $^{56,57}$. Using biotin switch approaches, Lindermayr and coworkers first identified $S$-nitrosated proteins in Arabidopsis leaf and cell suspension protein extracts after

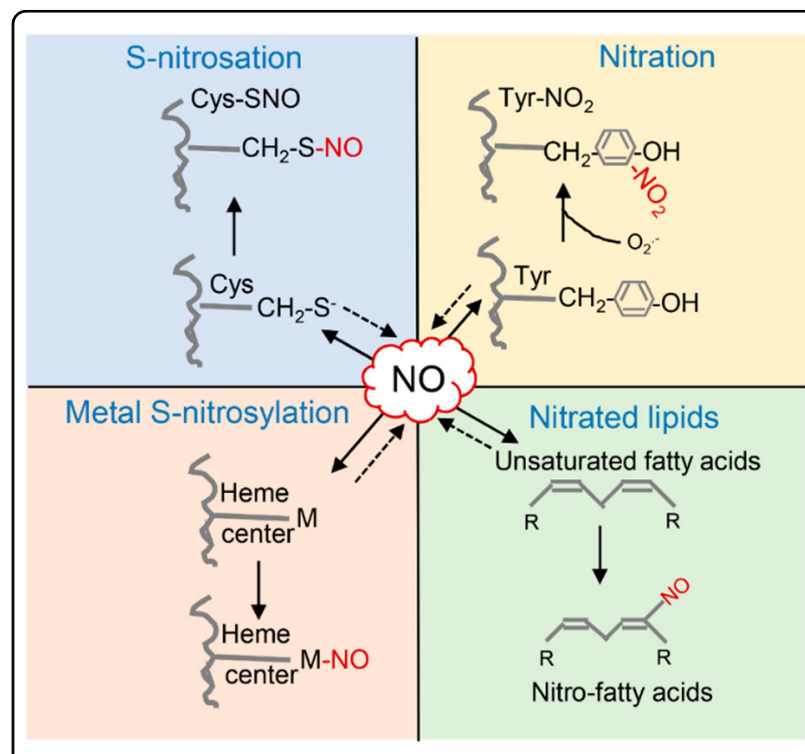

Fig. 2 NO-dependent posttranslational modifications in plants. Snitrosation, the covalent and reversible attachment of $\mathrm{NO}$ to a reactive thiol group of cysteine forming an S-nitrosothiol. Metal S-nitrosylation, in which an $\mathrm{NO}$ radical donates electrons and therefore reacts with transition metals. Tyrosine nitration is mediated by $\mathrm{ONOO}^{-}$, an NOderived species, resulting in the formation of a 3-nitrotyrosine residue. Nitration of unsaturated fatty acids forms nitro-fatty acids. All these processes except nitration are assumed to be reversible in plants. The dotted arrows indicate that all the products generated can release NO in plant cells 
exogenous NO application ${ }^{58}$. These proteins participate in various biological activities, such as metabolism, cytoskeleton, cellular signaling, redox homeostasis, and stress responses. That same year, an Arabidopsis gene with sequence similarity to that of $S$-nitroglutathione reductase (GSNOR), which regulates the formation and turnover of $S$-nitrosothiols (SNOs) in plants, was identified, and it was also found that AtGSNOR1 controls the extent of global $S$-nitrosylation in Arabidopsis ${ }^{59}$. Moreover, it has been reported that NO curbs the extent of cell death development during the hypersensitive response (HR) by $S$-nitrosation of NADPH oxidase, and Cys 890 was identified as the $S$-nitrosation site, thus inhibiting reactive oxygen species (ROS) production ${ }^{60}$. Several reports have pointed out that NO-triggered $S$-nitrosation of enzymes and proteins participating in the transport and signal transduction of distinct hormones exerts NO regulatory actions during plant development and defense responses ${ }^{9,61}$. For example, NO directly influences auxin perception and signaling by triggering the $S$-nitrosation of TRANSPORT INHIBITOR RESPONSE 1 (TIR1), an auxin receptor protein, at distinct (Cys 140 and Cys 480) residues $^{62}$. This PTM of TIR1 promotes its interaction with AUXIN/INDOLE-3-ACETIC ACID (AUX/IAA) proteins, which repress the transcription of auxinresponsive reporter genes, facilitating AUX/IAA degradation and auxin signal transduction. By promoting the $S$ nitrosation and degradation of positive regulators of abscisic acid (ABA), such as open stomata 1 /sucrose nonfermenting 1-related protein kinase 2-6 and ABAinsensitive 5, NO negatively regulates $\mathrm{ABA}$ signaling ${ }^{63,64}$. It has also been reported that $\mathrm{NO}$ negatively regulates cytokinin signaling by inhibiting phosphorylation activity via the $S$-nitrosation of Cys 115 of HISTIDINE PHOSPHOTRANSFER PROTEIN 1 (AHP1) ${ }^{65}$. To date, there is no doubt that this redox-based $S$-nitrosation constitutes an important strategy to convey NO signals into biological functions. A fundamentally critical question is how the signaling of $\mathrm{NO}$ as a redox signaling molecule via $S$ nitrosation is deactivated or downregulated. A growing body of evidence has revealed that GSNOR, an evolutionarily conserved NADH-dependent reductase, controls GSNO contents and subsequently global $S$-nitrosation levels, and this process is an important regulatory feature of NO bioactivity ${ }^{59}$. Currently, emerging evidence suggests that GSNOR-mediated denitrosylation has crucial roles in plant growth and development, disease tolerance, iron toxicity, thermotolerance, hypoxic responses, and salinity tolerance ${ }^{66-70}$, which are discussed in more detail later in horticultural crop species.

NO can also form complexes with the heme center of metalloproteins through metal $S$-nitrosylation reactions, impacting their activities ${ }^{29}$. Most studies have shown that hemoglobin, lipoxygenase, catalase, cytochrome c-oxidase, and ascorbate peroxidase are putative $S$-nitrosylation targets in plants ${ }^{32,71}$. Another important NO-mediated PTM is tyrosine nitration, leading to the generation of 3-nitrotyrosine, which is associated with nitro-oxidative damage in biological systems ${ }^{72}$. Tyrosine nitration has been extensively investigated in plants under adverse conditions. For example, nitroproteome analysis revealed an accumulation of tyrosine-nitrated proteins in sunflower seedlings exposed to high temperature ${ }^{73}$, leaves of Citrus plants under salinity stress ${ }^{74}$, and Arabidopsis plants under arsenic stress ${ }^{75}$. Generally, nitration improves the possibility of the protein being degraded by the proteasome ${ }^{76}$. Based on the above, the possible involvement of proteasomal degradation in conveying NO signals via tyrosine nitration needs to be better understood in plants.

More recently, nitration of unsaturated fatty acids, forming nitro-fatty acids, by NO-related species has been identified in plants ${ }^{77-79}$. The initial discovery of nitro-fatty acids in olive oils and olives promoted the identification and characterization of this molecule in plant species such as Arabidopsis, pea (Pisum sativum), and rice (Oryza sativa $)^{77,79}$. A few studies have reported that the accumulation of nitro-fatty acids such as nitro-linolenic acid and nitro-oleic acid were significantly induced by stresses ${ }^{79,80}$, and these molecules are probably novel key mediators in the defense mechanism mediated by NO in response to different biotic and abiotic stress situations.

Extensive research has established that NO pervades almost all aspects of plant development and the response to particular environmental cues ${ }^{16-21,81}$. A current central question is how NO, a single redox-active molecule, encodes complex information with particular specificity. Emerging evidence suggests that a multilayered molecular framework governs NO signaling specificity in a particular cellular microenvironment ${ }^{82}$. Predominantly, the temporal and spatial nature of different NO-based PTMs in discrete protein functions confers specificity to NO-based signaling $^{57,60,82}$. It is well established that cysteine thiols experience a redox continuum of alterations generating redoxrelated functional groups, including SNO, sulfenic acid (S-OH), disulfide (S-S), S-glutathionylation (S-SG), sulfinic acid $\left(\mathrm{S}-\mathrm{O}_{2} \mathrm{H}\right)$, and sulfonic acid formation $\left(\mathrm{S}-\mathrm{O}_{3} \mathrm{H}\right)^{83}$. It turns out that each modification leads to different conformational changes and, consequently, distinct cellular outcomes $^{84}$. Another well-established strategy in mammals for maintaining specificity in NO signaling is the proximity of NO to the target cystein ${ }^{82}$; however, this proximitybased mechanism has not been demonstrated in plants. Similar to other PTMs, the decoration of cysteine residues with NO is thought to be reversible, except for sulfonic acid $\left(\mathrm{S}-\mathrm{O}_{3} \mathrm{H}\right)^{82,83}$. Increasing evidence has demonstrated that reversal of the binding of cysteine residues with $\mathrm{NO}$, rather than their formation, constitutes an important strategy to convey specificity to NO-related redox signaling ${ }^{66,85}$. In 
this context, GSNOR regulates GSNO levels, and thioredoxin h5 (TRX h5), acting as a selective protein-SNO reductase, has emerged as a key mechanism for denitrosylation ${ }^{57,66,70,85}$. Arabidopsis seedlings with impaired GSNOR1 function exhibited increased levels of proteinSNO and deficiencies in development, immunity, and thermotolerance ${ }^{59,70,86}$. Emerging genetic and biochemical evidence indicates that plant TRX h5 discriminates between protein-SNO substrates, achieving specific, reversible protein-SNO signaling in plant immunity ${ }^{85}$. Emerging evidence has shown that another major route for transferring NO bioactivity is through impinging other ubiquitous and fundamental PTMs, such as SUMOylation, phosphorylation, persulfidation, and acetylation ${ }^{87}$. Through $S$-nitrosation, NO is able to modulate these PTMs, tailoring the cellular response to various stimuli. Finally, distinct differences between ROS and RNS can also establish specificity of redox signaling outputs ${ }^{88,89}$.

\section{NO regulates the development of horticultural crops}

Extensive knowledge on the multiple effects of $\mathrm{NO}$ on regulating plant development processes is available in model plant species such as Arabidopsis and economically important crop species, such as rice and wheat. Emerging evidence illustrates the value of $\mathrm{NO}$ in providing important horticultural traits (Fig. 1). Increased seed germination percentage and seedling growth, as well as biomass accumulation and yield in a number of vegetables, flowers, and fleshly fruits, have been reported after treatment with NO-releasing compounds (Table 1$)^{10,90-92}$. Furthermore, the recent identification of the first GSNOR enzyme in higher plants has opened the door to studying NO metabolism in plant growth and development under physiological and stressful conditions using a genetic approach. In Arabidopsis, it was found that AtGSNOR1 controls several pivotal processes of plant development ${ }^{86,93}$. For example, loss-of-function mutants in GSNOR1 in Arabidopsis resulted in a loss of apical dominance and reduced hypocotyl elongation ${ }^{86,93}$. Recently, multiple GSNOR-mediated developmental processes that regulate $S$-nitrosation have also been reported in tomato (Lycopersicon esculentum) seedlings. Knockdown of GSNOR resulted in an increased germination rate, severe inhibition of root and hypocotyl growth, substantially decreased photosynthesis, changes in leaf shape, and, important, reduced fruit yield ${ }^{94,95}$.

\section{NO breaks seed dormancy and germination of horticultural crops}

Seed germination is tightly regulated by a combination of external conditions and endogenous signals, maximizing growth and crop yield. For a long time, various nitrogenous compounds such as nitrate and nitrite have been used to break dormancy and stimulate seed germination in agricultural production ${ }^{96,97}$. Subsequent data have revealed that the promotion of dormant seed germination by these nitrogenous molecules probably occurs through NO generation. In initial experiments with lettuce (Lactuca sativa) seeds, NO stimulated seed germination in light-dependent situations ${ }^{91}$. In tomato seeds, NO scavengers maintained seed dormancy and counteracted the stimulating effect of fluridone ${ }^{98}$. It is well known that smoke is commonly used in horticulture to break dormancy and promote seed germination of some vegetables, such as lettuce and celery ${ }^{99}$. It is now clear that NO is among the essential active compounds responsible for seed germination stimulated by smoke. A seed of many edible fruit tree species such as apple (Malus domestica) and pomegranate (Punica granatum) shows the most pronounced and complex forms of dormancy, which is completely removed by several months of cold or warm stratification. Pretreatment with an NO donor ( $5 \mathrm{mM}$ Sodium nitroprusside (SNP)) promoted embryo germination by nearly $60 \%$ after 8 days, whereas it promoted germination by only $16 \%$ in nontreated seeds, and this effect was associated with the modulation of ROS metabolism by NO in the embryos at the early germination stage ${ }^{100}$. When seed dormancy is released, a large amount of $\mathrm{NO}$ accumulates in the axes of embryos of apple seeds and in the endosperm of Sechium deule $e^{100,101}$. Seed dissection suggests that the aleurone layer perceives and responds to NO during seed embryogenesis. Moreover, NO is able to protect the seed germination of various horticulture species under stress conditions, and presoaking attenuated the inhibition of seed germination and early growth of cucumber (Cucumis sativus) and pak choi (Brassica chinensis) under salt stress ${ }^{90,102}$.

A variety of phytohormones have been described to regulate the seed-to-seedling transition. It is well known that seed dormancy is strictly dependent on ABA concentration, whereas seed germination requires enhancement of gibberellic acid (GA) synthesis and signaling. During seed dormancy release, extensive cross-talk between NO and these two phytohormones has been observed $^{61,103}$. For example, endogenous NO production increased after ABA treatment, which was proposed to ameliorate the repressive effect of ABA, and NO accumulation generally decreases ABA contents in seeds ${ }^{104}$. Intensive amounts of research have been dedicated to unraveling the mechanisms underlying the interactions among the $\mathrm{NO}, \mathrm{ABA}$, and $\mathrm{GA}$ signaling networks during seed germination (Fig. 3), leading to the identification of several NO targets. Recently, evidence has revealed that NO enhances the degradation of ABSCISIC ACID INSENSITIVE 5 (ABI5) via $S$-nitrosation or promotes the degradation of group VIII ETHYLENE RESPONSE FACTORS (VIII ERFs) through the $N$-end rule pathway, resulting in seed germination in Arabidopsis ${ }^{64}$. Although 


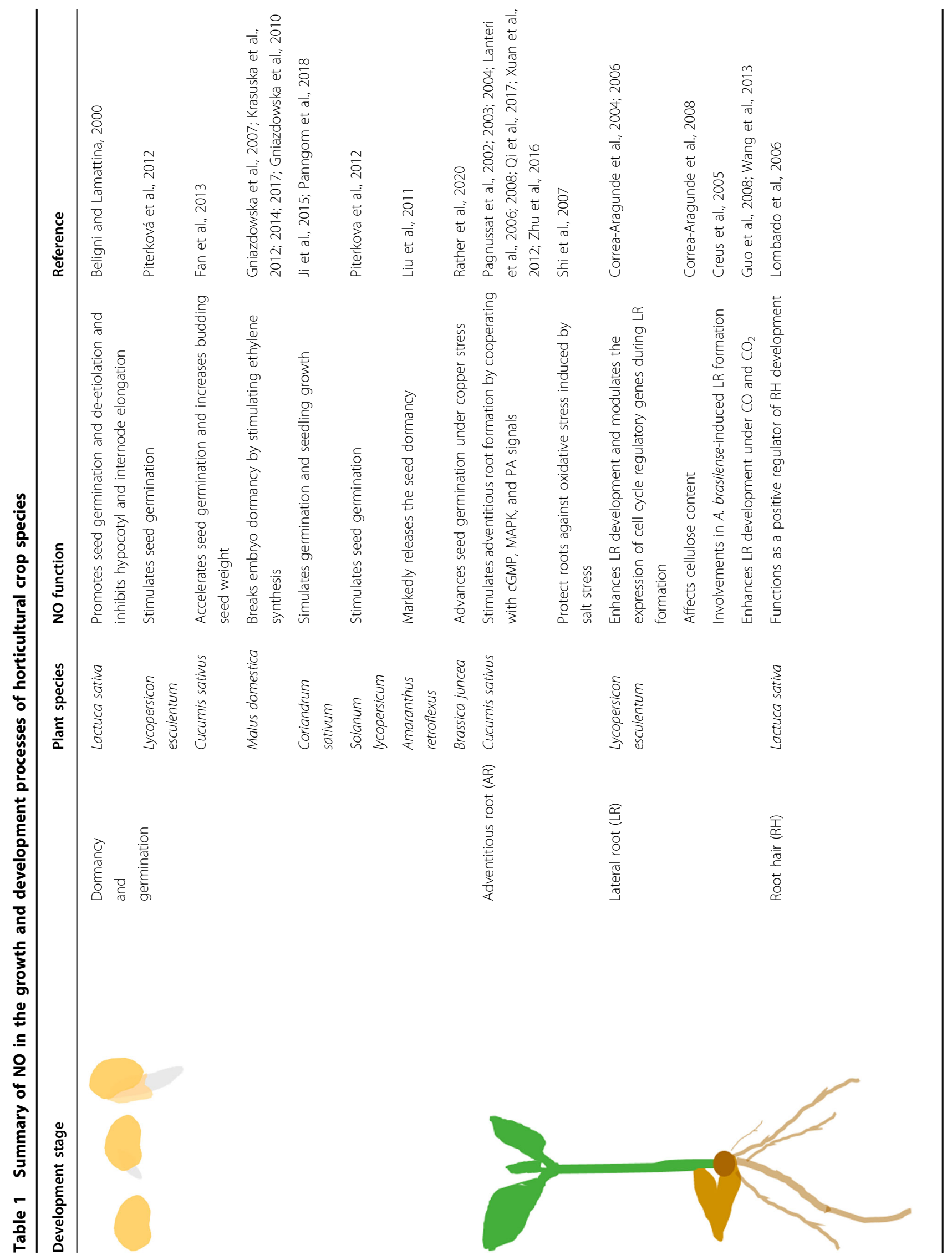




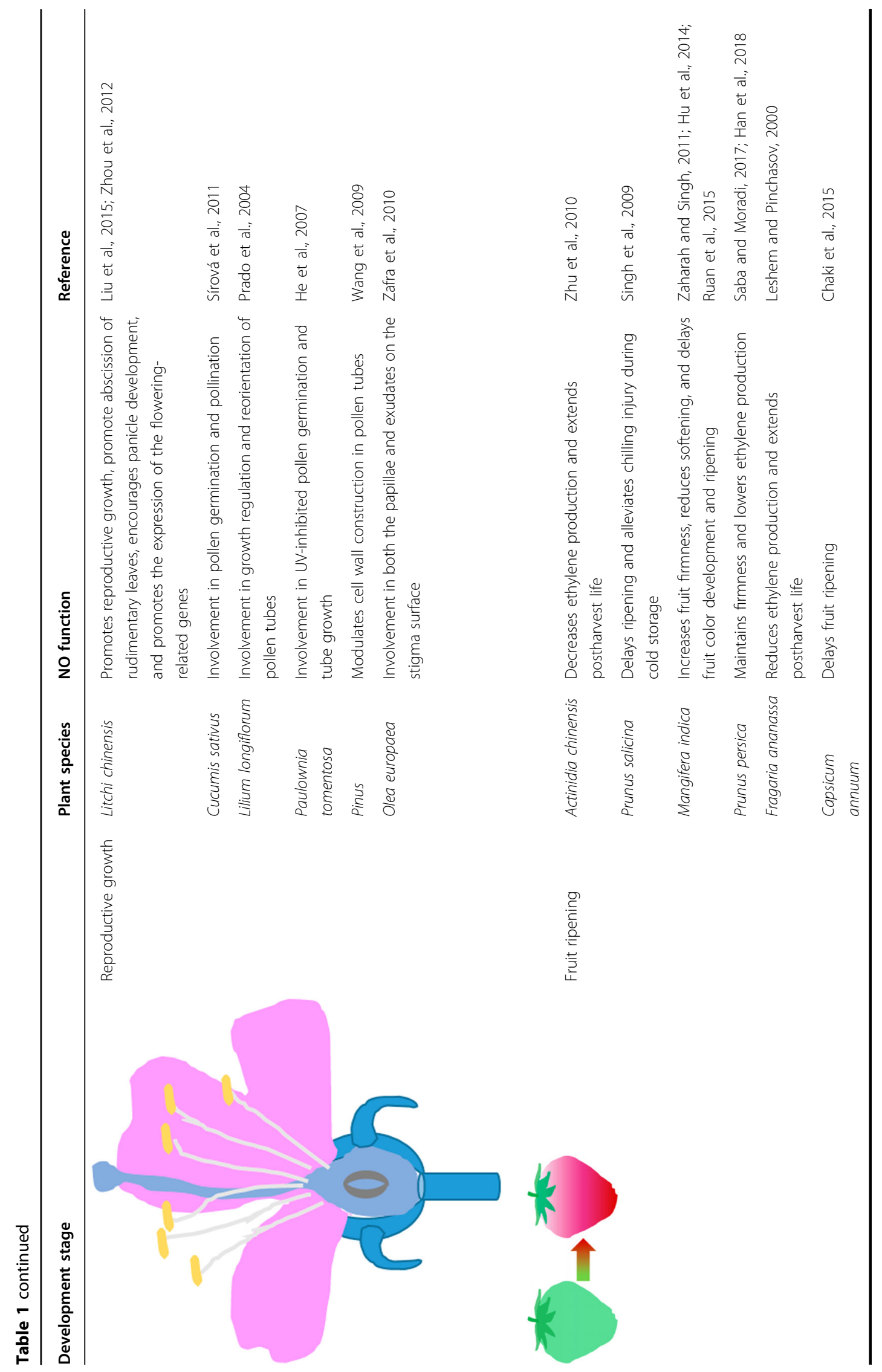




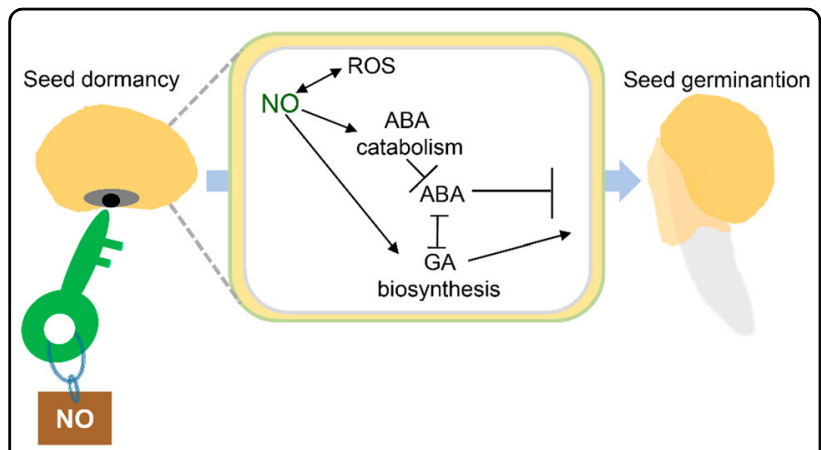

Fig. 3 Functional interactions among NO, $A B A$, and $G A$ s during seed germination. $N O$ induces $A B A$ catabolism and promotes GA biosynthesis, leading to dormancy release and germination. The arrows and bars indicate positive and inhibitory effects, respectively. ABA, abscisic acid; GA, gibberellic acid; ROS, reactive oxygen specie

still far from completely known, the mechanistic basis of NO-mediated seed dormancy release occurs presumably through synthesis and perception of $\mathrm{NO}$ in the aleurone layer, which in turn leads to ABA catabolism and GA biosynthesis in the embryo ${ }^{10}$. The resulting GA promotes cell wall loosening of EXPANSIN (EXPA) expression, facilitating the degradation of the physical barrier and allowing root emergence and germination ${ }^{105}$. It should be noted that during the regulation of certain biological processes, such as stomatal closure and antioxidant defense responses, $\mathrm{NO}$ acts downstream of $\mathrm{ABA}^{106}$. These results indicate a certain level of specificity in NO-ABA interaction mechanisms, which might depend on physiological events or the type of plant species, tissue or organ considered.

In addition to promoting seed germination, a recent study showed that $\mathrm{NO}$ also plays an important role in seed oil content and fatty acid composition ${ }^{107}$. Compared with the Arabidopsis wild type, the Arabidopsis mutant gsnor1 produced smaller seeds and reduced oil content. Moreover, the fatty acid composition was significantly altered in GSNOR1 RNAi2 transgenic lines, which showed lower GSNOR activity compared with that of the wild type, with increases in palmitic acid (C16:0), linoleic acid (C18:2), and linolenic acid (C18:3) and significant decreases in stearic acid (C18:0), oleic acid (C18:1), and arachidonic acid $(\mathrm{C} 20: 1)^{107}$. This study provides a potential approach to improve the seed oil content by regulating NO signaling in siliques of oil crop species.

\section{NO balances root growth and development of horticultural plants}

The root architecture system involves the coordinated growth of primary roots, lateral roots, and adventitious roots, which is tightly controlled by multiple genetic and environmental factors. In recent decades, a large number of experiments have highlighted the role of $\mathrm{NO}$ as a central regulator in auxin-orchestrated root growth and the development of plant roots ${ }^{9,24,108,109}$. Detailed information concerning this process was provided by a series of studies conducted by Lamattina and coworkers with cucumber and tomato plants ${ }^{24,92,108,110}$.

The linkage between $\mathrm{NO}$ and auxin was first reported in cucumber during adventitious root formation in 2002 (ref. ${ }^{108}$ ). The effects of NO application mimicked those of IAA, which stimulated adventitious root development in cucumber hypocotyls, whereas the NO scavenger completely blocked IAA-promoted adventitious root growth. A series of studies demonstrated that a number of secondary messengers participate in NO-mediated adventitious root growth. It has been observed that phosphatidic acid (PA) derived from both phospholipid signaling and the MAPK cascade acts as an agonist and probably works downstream of $\mathrm{NO}$ and auxin during this process ${ }^{92}$.

Lateral roots are a major determinant of root architecture, which is predominantly associated with auxin activation. Recently, NO has been considered to be a crucial downstream messenger in auxin signaling, promoting lateral root formation ${ }^{9}$. The first evidence on the stimulatory effect of $\mathrm{NO}$ on lateral root development was identified in a horticultural crop species. It was found that in tomato seedlings, the NO donor was able to induce lateral root emergence and elongation while inhibiting primary root growth in the same way that auxin does ${ }^{24}$. However, depletion of NO led to complete abolition of lateral root formation and partly restored primary root elongation. According to Correa-Aragunde et al. ${ }^{111}$, NO regulates the expression of genes involved in the cell cycle in tomato pericycle cells, which in turn results in lateral root formation. Under metal stress, it has been observed that $\mathrm{NO}$ is able to mitigate the inhibition of lateral root development caused by toxic soil pollutants such as cadmium and arsenic ${ }^{112}$. It was proposed that NO is linked to ROS, which cause auxin oxidation, thus maintaining auxin homeostasis and favoring lateral root formation ${ }^{112}$. Recent studies have also demonstrated that NO plays a critical role in controlling lateral root development triggered by other environmental stimuli and regulators, such as plant growth-promoting rhizobacteria ${ }^{113}$, carbon monoxide ${ }^{114}$, and elevated carbon dioxide ${ }^{115}$, in tomato and other horticultural crop species.

From the above effects of NO, it was inevitable that potential effects of $\mathrm{NO}$ in modulating the development of root hairs, which are derived from certain epidermal cells termed trichoblasts, be proposed. Not surprisingly, in 2006, NO was shown to promote the differentiation of trichoblasts in developing root hairs in lettuce plants ${ }^{116}$. Increased NO contents in the root hairs after 1-naphthyl acetic acid (NAA) treatment probably suggested that auxin-induced root hair formation is $\mathrm{NO}$ dependent. 
Current research suggests that $\mathrm{NO}$ appears to regulate root hair formation by acting on vesicle formation and trafficking, as NO synthesis mutants demonstrated altered vesicle trafficking and decreased root hair length. More recently, Lombardo and Lamattina reported that NO modulates root hair growth by acting on cytoskeletal organization by cooperating with $\mathrm{ABA}^{117}$.

Conversely, it has been reported that $\mathrm{NO}$ is able to inhibit root growth. Exogenous application of NO donors in tomato reduced overall primary root growth ${ }^{24}$. However, knowledge of the molecular mechanisms through which NO inhibits root growth is still limited. Using phenotypic, cellular, and genetic analyses in Arabidopsis, Fernández-Marcos et al. demonstrated that the disruption in auxin transport and response via a PIN1-dependent mechanism to high NO led to a reduction in root meristem activity ${ }^{118}$. This mechanism also underlies cadmium-induced inhibition of primary root growth through NO accumulation ${ }^{119}$. A direct influence of NO on auxin perception and signaling has been demonstrated based on the observation that TIR1, an auxin receptor protein, underwent $S$-nitrosation, enhancing TIR1-AUX/ IAA (transcriptional repressors) interaction, facilitating AUX/IAA degradation, and subsequently promoting gene expression $^{62}$. However, with respect to much of the progress concerning the understanding of the molecular mechanisms in Arabidopsis, whether these findings are of physiological relevance in horticultural crop species needs be thoroughly investigated.

\section{NO function in plant nutrition and abiotic stress in horticulture}

Horticultural production presents a significant challenge for nutrient management because many crops require large quantities of fertilizer to maximize yields and profits. Increased NO levels have been observed in different plant tissues following changes in nutrient supplies $^{26}$. Given the significant impact of NO on root system architecture, it is not surprising that NO plays essential roles in plants experiencing mineral nutrient imbalances.

To our knowledge, the first evidence indicating a direct modulation of plant mineral nutrition by $\mathrm{NO}$ originated from the ability of $\mathrm{NO}$ to cope with iron (Fe) deficiency symptoms in maize (Zea mays) ${ }^{120}$. Since then, extensive information supporting the pivotal role of $\mathrm{NO}$ in $\mathrm{Fe}$ nutrition, metabolism, transport, and availability in monocot and dicot plants has been accumulated, including various horticultural crop species ${ }^{121}$. In tomato, Fe deficiency causes rapid NO production in the root epidermis $^{25,122}$. The resulting NO positively regulates the expression of genes associated with Fe uptake, including LeFER, LeFRO1, and LeIRT1. Similarly, the enhancing effect of $\mathrm{NO}$ on the expression of Fe-acquisition genes has been observed in cucumber seedlings under Fe deficiency conditions $^{123}$. Thus, exogenous NO could alleviate the inhibition of photosynthesis and growth in Chinese cabbage (B. chinensis) cultivated under $\mathrm{Fe}$ deficiency ${ }^{124}$. These NO-mediated Fe deficiency responses occurred not only in herbaceous plant species such as Arabidopsis, tomato, peanut, and cucumber but also in fruit tree species grown in calcareous soil. For example, in the woody plant species Malus xiaojinensis, Fe deficiency stimulated marked accumulation of $\mathrm{NO}$ in the root elongation zone, whereas eliminating $\mathrm{NO}$ arrested root hair formation, blocked ferric chelate reductase activity, and prevented the upregulated expression of critical Fe-related genes ${ }^{125}$. Moreover, NO has been described to improve Fe utilization efficiency. In Arabidopsis, putrescine-induced NO could alter the cell wall composition, leading to the mobilization of Fe from roots to shoots and increases in available $\mathrm{Fe}$ levels ${ }^{126}$. These results are in contrast to those reported by Ye et al. on tomato plants, who suggested that elevation of NO might be an unfavorable factor under Fe deficiency because it could lead to $\mathrm{Fe}$ immobilization in the root apoplast ${ }^{127}$. It is possible that the discrepancy between these studies might be attributed to different plant species and treatment methods.

$\mathrm{NO}$ is emerging as a crucial player controlling the uptake and homeostasis of most macronutrients, including nitrogen $(\mathrm{N})$, phosphorus $(\mathrm{P})$, and potassium $(\mathrm{K})$. These elements are key components of many macromolecules, such as nucleotides, amino acids, and proteins. Nitrate $\left(\mathrm{NO}_{3}{ }^{-}\right)$, one of the most abundant sources of $\mathrm{N}$ in agricultural and horticultural systems, and NO are metabolically connected via NR, a key enzyme involved in both nitrogen acquisition and $\mathrm{NO}$ generation ${ }^{32,128}$. Increased $\mathrm{NO}_{3}{ }^{-}$supplies rapidly caused $\mathrm{NO}$ generation in the first few minutes, and $\mathrm{NO}$, in turn, participates in $\mathrm{NO}_{3}{ }^{-}$-mediated root architecture alterations, thus exhibiting involvement in $\mathrm{N}$ perception and uptake $\mathrm{e}^{129-131}$. On the other hand, NO regulates NR activity in the Chinese cabbage pak choi (B. chinensis) and tomato ${ }^{132,133}$, depending on the levels of $\mathrm{NO}_{3}{ }^{-}$supply, and the regulatory effects of $\mathrm{NO}$ on NR activity probably operate at the posttranslational level. This proposal was investigated later in Arabidopsis. More recently, biochemical and genetic approaches proved that $\mathrm{NO}$ is at the center of fine tuning nitrogen homeostasis in plants, as NO derived from nitrate assimilation can suppress both nitrate uptake and reduction by transporters and reductases, which in turn control its own generation ${ }^{128}$. Importantly, NO plays multiple roles in nitrogen-fixing symbiosis, which is performed mainly by legumes to enhance nitrogen acquisition. The sources and effects of NO have been extensively reviewed during root nodule symbiosis ${ }^{134,135}$. Under $\mathrm{P}$ and $\mathrm{K}$ nutrient deficiency, $\mathrm{NO}$ is involved in remodeling the root system and increasing the transport activity of these two elements ${ }^{26}$. In a study in white lupin (Lupinus 
albus), NO was shown to be involved in P deficiencyinduced cluster root formation and citrate exudation ${ }^{136}$. It has also been reported that $\mathrm{NO}$ acts upstream of ethylene in cell wall $\mathrm{P}$ reutilization in rice plants under $\mathrm{P}$ deficiency $^{137}$. After $\mathrm{K}$ restriction, NO significantly increased in plant cells ${ }^{138,139}$. The induced NO negatively regulates the Shaker-like $\mathrm{K}^{+}$channel (AKT1), indicating the role of $\mathrm{NO}$ in $\mathrm{K}$ homeostasis movement at the cellular level ${ }^{139}$. This phenomenon might be particularly relevant when plants are grown under stress conditions, such as drought and heat stress.

There are relatively few studies considering the relationship between $\mathrm{NO}$ and deficiencies in other nutrients in plants, such as copper $(\mathrm{Cu})$, zinc $(\mathrm{Zn})$, manganese $(\mathrm{Mg})$, and boron (B), which are required in low amounts but are toxic at high levels ${ }^{26,140,141}$. The most studied interactions between NO and micronutrients describe the beneficial behavior of $\mathrm{NO}$ under excessive amounts of $\mathrm{Cu}$. In periwinkle (Catharanthus roseus), a medicinal plant species, $\mathrm{NO}$ alleviates $\mathrm{Cu}$ toxicity by enhancing the activity of ATPase and stimulating the accumulation of secondary metabolites ${ }^{142}$. Similar results have also been observed in tomato seedlings under $\mathrm{Cu}$ stress ${ }^{143}$. Farag et al. reported that $\mathrm{NO}$ protected watermelon seedlings from $\mathrm{B}$-induced injury by reducing $\mathrm{B}$ accumulation and preventing oxidative damage ${ }^{141}$. However, micronutrient deficiencies are common in horticulture due to intensified agricultural practices and unbalanced fertilizer applications; $\mathrm{Zn}$ deficiency is the most widespread, followed by $\mathrm{B}, \mathrm{Mg}$, and $\mathrm{Cu}$ deficiencies ${ }^{144}$. In Arabidopsis, it has been reported that $\mathrm{NO}$ regulates $\mathrm{Mg}$ deficiency-induced root hair morphogenesis $^{145}$. However, there is a lack of knowledge about NO participation in horticultural crops exposed to micronutrient deficiencies.

In addition to nutrient deficiency, abiotic stresses such as salinity, drought, and extreme temperature are the main constraints drastically limiting horticultural crop productivity worldwide. Increasing amounts of data have indicated a crucial role for $\mathrm{NO}$ in a number of stress responses not only for model plant and major cereal crop species but also for horticultural crop species ${ }^{21,146}$. NO was recently proposed to mediate the plant response to salt stress on the basis of its toxicity and signaling functions. Under salt stress, NO has been found to improve seed germination and plant growth of pak choi (B. chinensis), sunflower (Helianthus annuus), and cucumber by alleviating oxidative stress or regulating secondary metabolism $^{90,147,148}$. In recent years, attention has been given to the NO-dependent PTM of proteins in response to salt stress. In olive leaves, salt stress induces a large amount of NO production and an increase in tyrosine-nitrated proteins, consequently leading to nitrosative stress in plant cells $^{149}$. Later, in sunflower seedlings, David et al. suggested that rapid NO accumulation and protein tyrosine nitration provided longevity to oil bodies for plant survival under salt stress ${ }^{150}$. Pretreatment of citrus (Citrus aurantium) plants sensitive to salinity with an NO donor enhanced the capacity of these plants to withstand high salinity. Further proteomic analysis suggested that protein $S$-nitrosation appears to mediate the acclimation of citrus seedlings to salt stress ${ }^{151}$. Compared with salt stress, drought stress is even more pervasive and damaging. In addition to model plant species, increasing evidence has revealed a function for NO in mitigating drought stress in horticultural production. For example, NO protected the ultrastructure of mesophyll cells and promoted adventitious root formation in marigold (Tagetes erecta) under drought stress ${ }^{152}$. Using two sugarcane genotypes ( $\mathrm{Sac}$ charum spp.) with different drought tolerances, Silveira et al. found that NO metabolism is more active in the roots of drought-tolerant genotypes than in those of drought-sensitive genotypes ${ }^{153}$. In this context, NO might stimulate root formation and enhance water uptake in the tolerant genotypes. Improved drought tolerance by $\mathrm{NO}$ in some model plant species is associated with its ability to enhance antioxidant system, proline, and osmolyte metabolism, and similar mechanisms have also been reported in various horticultural crop species, such as cucumber, tomato, and pepper ${ }^{154-156}$. Furthermore, various studies have shown that drought stress induces the synthesis and accumulation of NO in guard cells, which may also act as a mediator to minimize water loss by participating in ABA-mediated stomatal closure ${ }^{157}$. At the molecular level, NO treatment decreased the levels of drought-induced global DNA methylation of Dendrobium huoshanense $e^{158}$. Extremely high and low temperatures have deleterious effects on crop growth, development, and yield, particularly at critical phenophases. For example, low temperature is the primary constraint of tomato and pepper (Capsicum annuum) yield, since they are typical chilling-sensitive crop species. During the past decade, various studies have demonstrated an accumulation of $\mathrm{NO}$ in most cold-stressed crop species, and exogenous $\mathrm{NO}$ application triggers cold acclimation and tolerance ${ }^{159}$. Considering the importance of NO-dependent PTMs in NO signaling, increasing amounts of data are available on modifications of $S$-nitrosated proteins following cold exposure in horticultural crop species such as citrus and Brassica juncea ${ }^{160,161}$. Given that the identified S-nitrosated proteins in cold-stressed plants are mostly involved in metabolism, future studies should focus on the downstream signaling cascades that can be activated by NObased $S$-nitrosation. Similarly, rapid NO production has also been observed in heat-stressed crops, and NO improves heat tolerance by decreasing ROS contents ${ }^{162}$. High temperature also stimulates $\mathrm{NO}$ metabolism, and the total SNO content was shown to increase in heatstressed pea, citrus, and Brassica ${ }^{163,164}$. With the 


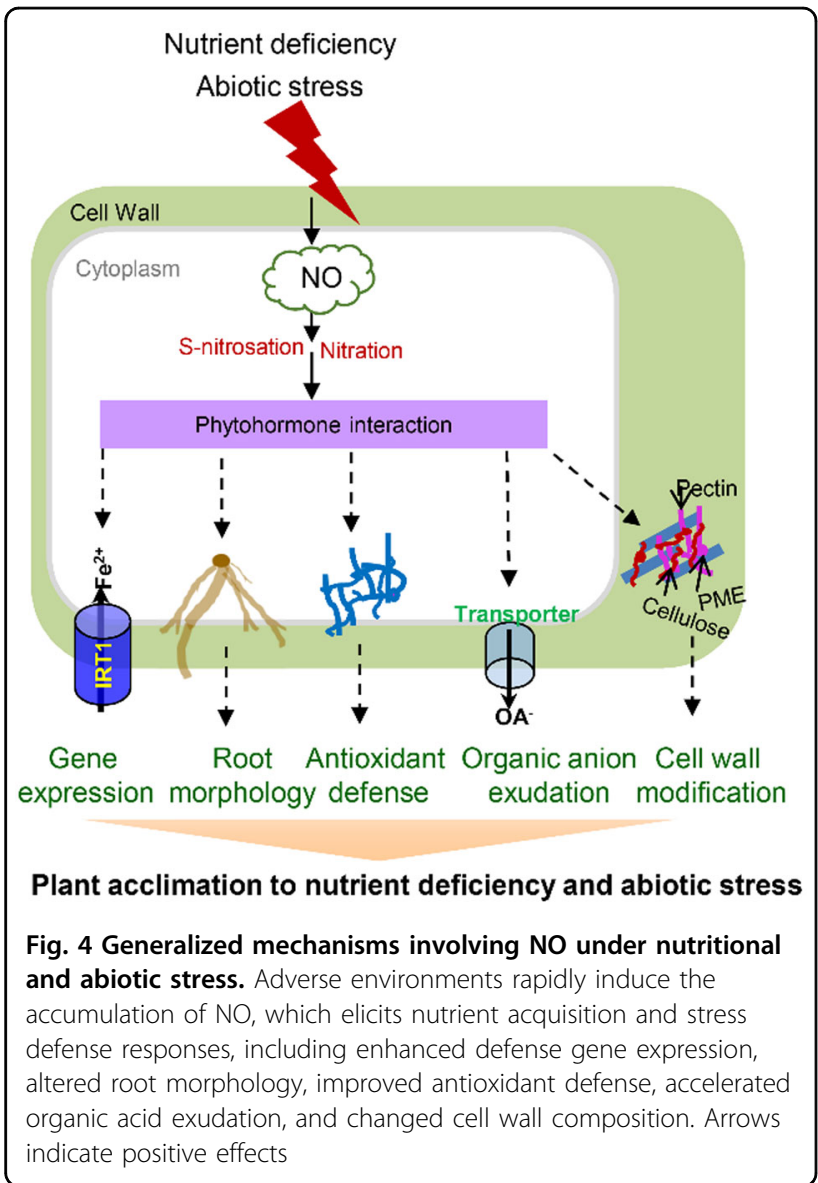

challenges imposed by global warming, unexpected and increased flood-induced hypoxia will be major agricultural and horticultural production constraints in the near future. During hypoxia, a rapid NO burst has been reported in various plant species, and NO is an essential component to modulate plant acclimation to hypoxic conditions ${ }^{165}$. Overall, by conveying its bioactivity through PTM and interacting with various phytohormones, NO improves plant performance under conditions of nutrient and abiotic stress (Fig. 4).

\section{NO activates disease resistance in horticultural crops}

Pathogens and pests reduce the yield and quality of horticultural crops, causing substantial economic losses and reducing food security across the globe. To survive, crops must sense invading pathogens and mount an effective defense response against these harmful agents. Among these mechanisms are physical barriers such as cell wall thickness and degree of lignification, preformed chemical compounds such as cocktails of diverse secondary metabolites and various transcriptional pathways $^{166,167}$. Insights from decades of plant-pathogen interaction studies have demonstrated that the activation of the signaling network ensures an induced response that is quantitative, timely and coordinated with other activities of the host cells ${ }^{168}$. One of the most prominent generalist messengers is $\mathrm{NO}$, known as the component of the nitrosative burst. In combination with salicylic acid (SA), NO behaves as a crucial component of the plant immune response and participates together with ROS in activating the $\mathrm{HR}$ and cell death during incompatible plant-pathogen interactions ${ }^{9,169}$.

$\mathrm{NO}$ involvement in the plant immune response was first detected in potato, in which an NO donor induced the accumulation of the potato phytoalexin rishitin, an endogenous antibiotic compound ${ }^{13}$. One year later, it was further proven, following exogenous NO application, that NO could preserve chlorophyll levels in Phytophthora infestans-infected potato leaves ${ }^{170}$. Since then, knowledge of the involvement of $\mathrm{NO}$ in local and systemic responses against biotic stress has increased greatly. Currently, although some controversy still surrounds the production and turnover of $\mathrm{NO}$ in plant immunity, the ensuing early NO burst is thought to orchestrate a plethora of strategies for defense against pathogens. A main strategy is the HR, a localized activation of programmed cell death (PCD) surrounding the infection sites restricting the spread and replication of the pathogens within the plant beyond the initial infection site ${ }^{171}$. Arabidopsis infected with Pseudomonas syringae pv. tomato DC3000 induced $\mathrm{Ca}^{2+}$ influx into the cytosol, activating $\mathrm{CaM}$, which then acts to induce downstream NO synthesis, leading to the $\mathrm{HR}^{172}$. Another common feature of pathogen- or elicitor-induced HRs is the rapid accumulation of ROS. At present, a wealth of information supports the simultaneous engagement of nitrosative and oxidative bursts in the plant HR response, and a balance between ROS and NO is required for efficient induction of hypersensitive cell death ${ }^{173}$. For example, both NO and ROS are required for the onset of apoptotic cell death in adjacent cells of oat plants during avirulent crown rust fungal infection ${ }^{174}$. In the cross-talk between pelargonium (Pelargonium peltatum) leaves and Botrytis cinerea, only an early NO burst concomitant with a periodic increase in $\mathrm{H}_{2} \mathrm{O}_{2}$ concentration was observed in a resistant cultivar $^{175}$. Increasing only one component of the NO-ROS binary system failed to induce hypersensitive cell death in both soybean and tobacco cell suspensions ${ }^{89,176}$, pointing to $\mathrm{NO}$ along with ROS as essential components in regulating hypersensitive cell death in pathogen-triggered responses. Moreover, further studies suggested the involvement of $\mathrm{NO}$ in cell-to-cell spreading of the HR rather than just in triggering cell death ${ }^{177}$. The immune response is actually mediated by a complex interconnected network that involves various phytohormones and other signaling intermediates. Recent studies have indicated that NO is integrated within this immune network, as it coordinates 
with several classic pathways, such as SA-related or JA/ ethylene-related signaling events ${ }^{178}$.

NO via GSNO-mediated $S$-nitrosation could contribute to well-known immunity signaling pathways and thus has a profound effect on plant immune responses. Immunohistochemical analysis showed that, in sunflower $(H$. annuus) hypocotyls after infection by the fungus Plasmopara halstedii, GSNO accumulation was redistributed to epidermal cells, which is the site of penetration by this fungus ${ }^{179}$. The authors suggested that GSNO appears to be a mobile signal and might contribute to sunflower resistance. As mentioned above, GSNOR controls GSNO contents and subsequently global $S$-nitrosation levels. GSNOR1-silenced tomato plants presented increased levels of protein $S$-nitrosation, resulting in substantial cell death in response to pathogen infection ${ }^{180}$. It is well known that SA plays important roles in local and systemic responses against pathogen infection, and GSNOR could regulate both the biosynthesis and signaling of SA. In gsnor1-3 Arabidopsis mutants, SA-dependent gene expression in response to diminished SA accumulation was compromised, whereas enhanced activity of AtGSNOR1 increased SA-dependent gene expression ${ }^{60}$. Furthermore, in the SA signaling pathway, a large number of proteins undergo $S$-nitrosation ${ }^{181}$. For instance, the $S$ nitrosation of SA-binding protein 3 at Cys 280 suppressed SA-binding capacity and carbonic anhydrase activity ${ }^{182}$, both of which are required for pathogen resistance. It has also been proven that the plant immune response requires conformational changes to NON EXPRESSER OF PATHOGENESIS RELATED 1 (NPR1) via $S$-nitrosation at a specific reactive cysteine, which facilitates the oligomerization of NPR1 and compromises NPR1-mediated disease resistance ${ }^{68}$. Another two potential targets in the SA signaling pathway for $S$-nitrosation are TGA1 and SRG1 $1^{183,184}$, of which $S$-nitrosation leads to a boost in the immune response. These data illustrate the importance of NO via GSNO-mediated $S$-nitrosation in SA-dependent immune responses.

\section{NO as a potent fumigant for postharvest control}

Numerous studies during the past few years have demonstrated that NO content progressively declines during fruit ripening, with concomitant increases in protein nitration and nitrosation. It has also been suggested that exogenous NO treatment could delay fruit ripening, prevent chilling damage, and affect redox dynamics by improving antioxidant activity and, consequently, increasing nutritional value (Table 1$)^{185,186}$. Here, to avoid repeating, we mainly discussed how NO is a potent fumigant for postharvest control. Postharvest diseases and pests of fruits and vegetables lead to severe losses during handling, transportation, and storage. A large number of studies have shown that NO can maintain the sensory and nutritional attributes and extend the shelf-life of many perishables, including fresh fruits such as strawberry, apple, kiwi, and plum fruits ${ }^{187-189}$, as well as vegetables such as mushrooms, cucumbers, lettuce, and broccoli ${ }^{190-192}$. Increasing evidence shows that $\mathrm{NO}$ can act as a fumigant against a wide range of postharvest diseases and pests and has the potential to become an effective and safe synthetic chemical alternative for disease and pest control of fresh produce. It has been demonstrated that NO fumigation is effective for controlling spotted wing Drosophila in strawberry and sweet cherry fruits ${ }^{193,194}$, western flower thrips and aphids in lettuce ${ }^{195,196}$, and codling moths in apple fruis ${ }^{197}$. In recent years, there has been no doubt that NO is effective against all insect and mite species at different life stages, including the egg and pupa stages. It should be noted that small insects such as aphids and thrips in field crops are more sensitive to NO than storedproduct insects such as flour beetles. Moreover, NO has obvious inhibitory effects on perishable pathogen-induced diseases. Treatment of cut slices of apple fruits and lettuce with NO prevents surface browning ${ }^{198,199}$. Lai et al. observed that NO donors significantly improved the resistance of apple fruits to Penicillium expansum ${ }^{200}$. Similarly, Hu et al. showed that NO inhibited anthracnose (caused by Colletotrichum gloeosporioides) in pitaya fruits by activating defense responses and slowing senescence ${ }^{201}$. Supplementation of preharvest green mature tomato fruits with L-arginine, the precursor of $\mathrm{NO}$, induced defenses against postharvest Botrytis cinerea diseases in tomato fruits $^{202}$. It should be noted that NO fumigation must be conducted under ultralow oxygen conditions and terminated by $\mathrm{N}_{2}$ flushing, avoiding damage to delicate fresh produce caused by nitrogen dioxide, which is spontaneously produced by $\mathrm{NO}$ and $\mathrm{O}_{2}$. In recent years, $\mathrm{NO}$ has also been found to extend the postharvest life of numerous types of flowers ${ }^{188,203,204}$. Although a few studies have pointed to the role of $S$-nitrosation in the potential molecular mechanisms of postharvest disease and pest control, further research is needed to support this conclusion.

NO also diminishes pesticide toxicity and reduces residue in horticultural crops, preventing possible health risks. Pesticide-induced alteration of redox status, resulting from overaccumulation of ROS, negatively affects plant growth and development. As a redox active molecule, NO confers pesticide tolerance to plants in part by mediating antioxidant defense systems ${ }^{205-208}$. In potato plants, NO donors strongly protected against cellular damage induced by diquat and paraquat, two methylviologen herbicides, as a result of the ability of NO to scavenge $\operatorname{ROS}^{206}$. In soybean seedlings, $\mathrm{NO}$ is able to scavenge ROS induced by the herbicide lactofen and protects plants from oxidative damage. Furthermore, NO application could significantly reduce pesticide residue in plants. This phenomenon could be due to NO-mediated 
enhancement of some specific enzymes and processes involved in pesticide detoxification, such as the following: hydrolytic enzymes; glutathione; and other conjugation mechanisms, cytochrome P450 oxidases, and peroxidases ${ }^{209,210}$. Yin et al. reported that NO enhanced GSH biosynthesis and promoted the metabolism of chlorothalonil, a widely used fungicide, in tomato seedlings ${ }^{211}$. On this basis, there is no doubt that NO has strong potential for use in horticultural crop protection and could reduce pesticide residue in food crops.

\section{Conclusions and perspectives}

It is now becoming apparent that NO displays myriad physiological and biological functions during the growth, development, environmental interactions, and postharvest storage of horticultural crops. While research on model plant species has provided an abundance of valuable information on horticultural crop species, the potential use of NO in horticulture is still in its infancy, as the application of $\mathrm{NO}$ donors is hindered by the instability of these compounds. In this scenario, a promising strategy is the entrapment of $\mathrm{NO}$ donors in nanomaterials, which has been successfully applied in the biomedical field. For the first time, Oliveira et al. successfully synthesized NOreleasing chitosan nanoparticles that protected maize plants from salt stress ${ }^{212}$. Therefore, this new technique might have a significant economic impact on both agriculture and horticulture.

$S$-nitrosation is of particular importance for transducing NO bioactivity during plant growth and stress responses. Given that the $S$-nitrosated proteins identified so far are mostly involved in metabolism, future studies should focus on the downstream signaling cascades activated via $S$-nitrosation. On the other hand, stress-induced NO strongly impacts defense-related gene expression, and attention should be paid particularly to the identification and characterization of major transcription factors that are $S$-nitrosated in crop plants.

With the development of sequencing technology, the genomes of some horticultural crop species have been sequenced. Genetic tractability and myriad molecular tools may enable ideal NO-related traits identified in model plant species to be transferred into horticultural species and subsequent production, although genome editing remains challenging.

\section{Acknowledgements \\ This work was financially supported by the National Natural Science Foundation of China (22006130, 31872167), the Zhejiang Provincial Natural Science Foundation of China (LQ21C150007), the Open Project Program of State Key Laboratory of Rice Biology (20200401), and the Fundamental Research Funds for the Central Universities (2020QNA6013).}

\section{Author details}

${ }^{1}$ MOE Key Laboratory of Environment Remediation and Ecological Health, College of Environmental \& Resource Sciences, Zhejiang University, 310058
Hangzhou, China. ${ }^{2}$ Interdisciplinary Research Academy, Zhejiang Shuren University, 310015 Hangzhou, China. ${ }^{3}$ Zhejiang Provincial Cultivated Land Quality and Fertilizer Administration Station, Hangzhou, China

\section{Author contributions}

C.S., Y.Z., and X.L. planned the outline of the review; Y.Z. and L.L. gathered the available literature; and C.S. and X.L. wrote the manuscript, with substantial contributions from B.L., C.J., Y.Z., X.L., and L.L.

\section{Conflict of interest}

The authors declare no competing interests.

Received: 26 September 2020 Revised: 4 January 2021 Accepted: 11 January 2021

Published online: 01 April 2021

\section{References}

1. Wendehenne, D., Durner, J. \& Klessig, D. F. Nitric oxide: a new player in plant signalling and defence responses. Curr. Opin. Plant Biol. 7, 449-455 (2004).

2. Wendehenne, D., Pugin, A., Klessig, D. F. \& Durner, J. Nitric oxide: comparative synthesis and signaling in animal and plant cells. Trends Plant Sci. 6, 177-183 (2001)

3. Bredt, D. S. \& Snyder, S. H. Nitric oxide, a novel neuronal messenger. Neuron 8, 3-11 (1992).

4. Knowles, R. G. \& Moncada, S. Nitric oxide synthases in mammals. Biochem. J. 298, 249-258 (1994).

5. Stamler, J. S. et al. Nitric oxide circulates in mammalian plasma primarily as an S-nitroso adduct of serum albumin. Proc. Natl Acad. Sci. USA 89, 7674-7677 (1992).

6. Cox, M. A. et al. Beyond neurotransmission: acetylcholine in immunity and inflammation. J. Intern. Med. 287, 120-133 (2020).

7. Klepper, L. Nitric oxide (NO) and nitrogen dioxide $\left(\mathrm{NO}_{2}\right)$ emissions from herbicide-treated soybean plants. Atmos. Environ. 13, 537-542 (1979).

8. Delledonne, M., Xia, Y., Dixon, R. A. \& Lamb, C. Nitric oxide functions as a signal in plant disease resistance. Nature 394, 585-588 (1998).

9. Yu, M., Lamattina, L., Spoel, S. H. \& Loake, G. J. Nitric oxide function in plant biology: a redox cue in deconvolution. New Phytol. 202, 1142-1156 (2014)

10. Sanz, L. et al. Nitric oxide (NO) and phytohormones crosstalk during early plant development. J. Exp. Bot. 66, 2857-2868 (2015).

11. Astier, J., Gross, I. \& Durner, J. J. Nitric oxide production in plants: an update. J. Exp. Bot. 69, 3401-3411 (2018).

12. Kolbert, Z. S. et al. A forty year journey: the generation and roles of $\mathrm{NO}$ in plants. Nitric Oxide 93, 53-70 (2019).

13. Noritake, T., Kawakita, K. \& Doke, N. Nitric oxide induces phytoalexin accumulation in potato tuber tissues. Plant Cell Physiol. 37, 113-116 (1996).

14. Durner, J., Wendehenne, D. \& Klessig, D. F. Defense gene induction in tobacco by nitric oxide, cyclic GMP, and cyclic ADP-ribose. Proc. Natl Acad. Sci. USA 95, 10328-10333 (1998).

15. Modolo, L. V., Cunha, F. Q., Braga, M. R. \& Salgado, I. Nitric oxide synthasemediated phytoalexin accumulation in soybean cotyledons in response to the Diaporthe phaseolorumf. sp. meridionalis elicitor. Plant Physiol. 130, 1288-1297 (2002).

16. He, Y. et al. Nitric oxide represses the Arabidopsis floral transition. Science $\mathbf{3 0 5}$ 1968-1971 (2004).

17. Bethke, P. C., Libourel, I. G. \& Jones, R. L. Nitric oxide reduces seed dormancy in Arabidopsis. J. Exp. Bot. 57, 517-526 (2006).

18. Sun, C. et al. Nitrate reductase-mediated early nitric oxide burst alleviates oxidative damage induced by aluminum through enhancement of antioxidant defenses in roots of wheat (Triticum aestivum). New Phytol. 201, 1240-1250 (2014).

19. Neill, S. et al. Nitric oxide, stomatal closure, and abiotic stress. J. Exp. Bot. 59, 165-176 (2008).

20. Qiao, W. \& Fan, L. M. Nitric oxide signaling in plant responses to abiotic stresses. J. Integr. Plant Biol. 50, 1238-1246 (2008).

21. Fancy, N. N., Bahlmann, A. K. \& Loake, G. Nitric oxide function in plant abiotic stress. Plant Cell Environ. 40, 462-472 (2017).

22. González-Gordo, S. et al. Nitric oxide-dependent regulation of sweet pepper fruit ripening. J. Exp. Bot. 70, 4557-4570 (2019). 
23. Airaki, M. et al. Metabolism of reactive oxygen species and reactive nitrogen species in pepper (Capsicum annuum L.) plants under low temperature stress. Plant Cell Environ. 35, 281-295 (2012).

24. Correa-Aragunde, N., Graziano, M. \& Lamattina, L. Nitric oxide plays a central role in determining lateral root development in tomato. Planta 218, 900-905 (2004).

25. Graziano, M. \& Lamattina, L. Nitric oxide accumulation is required for molecular and physiological responses to iron deficiency in tomato roots. Plant J. 52, 949-960 (2007).

26. Buet, A., Galatro, A., Ramos-Artuso, F. \& Simontacchi, M. Nitric oxide and plant mineral nutrition: current knowledge. J. Exp. Bot. 70, 4461-4476 (2019).

27. Manjunatha, G., Lokesh, V. \& Neelwarne, B. Nitric oxide in fruit ripening: trends and opportunities. Biotechnol. Adv. 28, 489-499 (2010).

28. León, J. \& Costa-Broseta, Á. Present knowledge and controversies, deficiencies, and misconceptions on nitric oxide synthesis, sensing, and signaling in plants. Plant Cell Environ. 43, 1-15 (2020).

29. Besson-Bard, A., Pugin, A. \& Wendehenne, D. New insights into nitric oxide signaling in plants. Annu. Rev. Plant Biol. 59, 21-39 (2008).

30. Rockel, P., Strube, F., Rockel, A., Wildt, J. \& Kaiser, W. M. Regulation of nitric oxide (NO) production by plant nitrate reductase in vivo and in vitro. J. Exp. Bot. 53, 103-110 (2002)

31. Yamasaki, H. Nitrite-dependent nitric oxide production pathway: implications for involvement of active nitrogen species in photoinhibition in vivo. Philos. Trans. R. Soc. Lond. B Biol. Sci. 355, 1477-1488 (2000).

32. Chamizo-Ampudia, A., Sanz-Luque, E., Llamas, A., Galvan, A. \& Fernandez, E. Nitrate reductase regulates plant nitric oxide homeostasis. Trends Plant Sci. 22, 163-174 (2017)

33. Kaiser, W. M., Planchet, E. \& Rümer, S. Nitrate reductase and nitric oxide. Annu. Plant Rev 42, 127-145 (2018).

34. García-Mata, C. \& Lamattina, L. Abscisic acid, nitric oxide and stomatal closure-is nitrate reductase one of the missing links? Trends Plant Sci. 8, 20-26 (2003).

35. Desikan, R., Griffiths, R., Hancock, J. \& Neill, S. A new role for an old enzyme: nitrate reductase-mediated nitric oxide generation is required for abscisic acid-induced stomatal closure in Arabidopsis thaliana. Proc. Natl Acad. Sci. USA 99, 16314-16318 (2002).

36. Seligman, K. et al. Floral transition and nitric oxide emission during flower development in Arabidopsis thaliana is affected in nitrate reductase-deficient plants. Plant Cell Physiol. 49, 1112-1121 (2008).

37. Kolbert, Z., Bartha, B. \& Erdei, L. Exogenous auxin-induced NO synthesis is nitrate reductase-associated in Arabidopsis thaliana root primordia. J. Plant Physiol. 165, 967-975 (2008).

38. Campbell, W. Structure and function of eukaryotic NAD (P) $\mathrm{H}$ : nitrate reductase. Cell. Mol. Life Sci. 58, 194-204 (2001).

39. Stöhr, C., Strube, F., Marx, G., Ullrich, W. R. \& Rockel, P. A plasma membranebound enzyme of tobacco roots catalyses the formation of nitric oxide from nitrite. Planta 212, 835-841 (2001)

40. Meyer, C. \& Stöhr, C. Soluble and plasma membrane-bound enzymes involved in nitrate and nitrite metabolism. Photosynthetic nitrogen assimilation and associated carbon and respiratory metabolism 49-62 (Springer, 2002).

41. Moche, M. et al. Effect of nitrate supply and mycorrhizal inoculation on characteristics of tobacco root plasma membrane vesicles. Planta 231, 425 (2010).

42. Chamizo-Ampudia, A. et al. A dual system formed by the ARC and NR molybdoenzymes mediates nitrite-dependent NO production in Chlamydomonas. Plant Cell Environ. 39, 2097-2107 (2016).

43. Godber, B. L. et al. Reduction of nitrite to nitric oxide catalyzed by xanthine oxidoreductase. J. Biol. Chem. 275, 7757-7763 (2000).

44. Gupta, K. J., Stoimenova, M. \& Kaiser, W. M. In higher plants, only root mitochondria, but not leaf mitochondria reduce nitrite to $\mathrm{NO}$, in vitro and in situ. J. Exp. Bot. 56, 2601-2609 (2005).

45. Gupta, K. J. \& Igamberdiev, A. U. The anoxic plant mitochondrion as a nitrite: NO reductase. Mitochondrion 11, 537-543 (2011).

46. Zemojtel, T. et al. Plant nitric oxide synthase: a never-ending story? Trends Plant Sci. 11, 524-525 (2006).

47. Barroso, J. B. et al. Localization of nitric-oxide synthase in plant peroxisomes. J. Biol. Chem. 274, 36729-36733 (1999).

48. Guo, F. Q., Okamoto, M. \& Crawford, N. M. Identification of a plant nitric oxide synthase gene involved in hormonal signaling. Science 302, 100-103 (2003).

49. Moreau, M., Lee, G. I., Wang, Y., Crane, B. R. \& Klessig, D. F. AtNOS/AtNOA1 is a functional Arabidopsis thaliana CGTPase and not a nitric-oxide synthase. J. Biol. Chem. 283, 32957-32967 (2008).
50. Foresi, N. et al. Characterization of a nitric oxide synthase from the plant kingdom: NO generation from the green alga Ostreococcus tauri is light irradiance and growth phase dependent. Plant Cell 22, 3816-3830 (2010).

51. Jeandroz, S. et al. Occurrence, structure, and evolution of nitric oxide synthase-like proteins in the plant kingdom. Sci. Signal. 9, re2 (2016).

52. Rümer, S., Gupta, K. J. \& Kaiser, W. M. Plant cells oxidize hydroxylamines to NO. J. Exp. Bot. 60, 2065-2072 (2009).

53. Tun, N. N. et al. Polyamines induce rapid biosynthesis of nitric oxide (NO) in Arabidopsis thaliana seedlings. Plant Cell Physiol. 47, 346-354 (2006).

54. Wimalasekera, R., Tebartz, F. \& Scherer, G. F. Polyamines, polyamine oxidases and nitric oxide in development, abiotic and biotic stresses. Plant Sci. 181, 593-603 (2011).

55. Friebe, A. \& Koesling, D. Regulation of nitric oxide-sensitive guanylyl cyclase Circ. Res. 93, 96-105 (2003).

56. Stamler, J. S. et al. S-nitrosylation of proteins with nitric oxide: synthesis and characterization of biologically active compounds. Proc. Natl Acad. Sci. USA 89, 444-448 (1992).

57. Feng, J., Chen, L. \& Zuo, J. Protein S-nitrosylation in plants: current progresses and challenges. J. Integr. Plant Biol. 61, 1206-1223 (2019).

58. Lindermayr, C., Saalbach, G. \& Durner, J. Proteomic identification of Snitrosylated proteins in Arabidopsis. Plant Physiol. 137, 921-930 (2005).

59. Feechan, A. et al. A central role for S-nitrosothiols in plant disease resistance. Proc. Natl Acad. Sci. USA 102, 8054-8059 (2005).

60. Yun, B. W. et al. S-nitrosylation of NADPH oxidase regulates cell death in plant immunity. Nature 478, 264-268 (2011).

61. Freschi, L. Nitric oxide and phytohormone interactions: current status and perspectives. Front. Plant Sci. 4, 398 (2013).

62. Terrile, M. C. et al. Nitric oxide influences auxin signaling through S-nitrosylation of the Arabidopsis TRANSPORT INHIBITOR RESPONSE 1 auxin receptor. Plant J. 70, 492-500 (2012).

63. Wang, P. et al. Nitric oxide negatively regulates abscisic acid signaling in guard cells by S-nitrosylation of OST1. Proc. Natl Acad. Sci. USA 112, 613-618 (2015).

64. Albertos, P. et al. S-nitrosylation triggers $\mathrm{ABI} 5$ degradation to promote seed germination and seedling growth. Nat. Commun. 6, 1-10 (2015).

65. Feng, J. et al. S-nitrosylation of phosphotransfer proteins represses cytokinin signaling. Nat. Commun. 4, 1-9 (2013).

66. Malik, S. I., Hussain, A., Yun, B. W., Spoel, S. H. \& Loake, G. J. GSNOR-mediated de-nitrosylation in the plant defence response. Plant Sci. 181, 540-544 (2011)

67. Zhang, J. \& Liao, W. Protein S-nitrosylation in plant abiotic stresses. Funct. Plant Biol. 47, 1-10 (2020).

68. Tada, Y. et al. Plant immunity requires conformational charges of NPR1 via Snitrosylation and thioredoxins. Science 321, 952-956 (2008).

69. Zhan, N. et al. S-nitrosylation targets GSNO reductase for selective autophagy during hypoxia responses in plants. Mol. Cell 71, 142-154.e6 (2018).

70. Li, B., Sun, C., Lin, X., \& Busch, W. The emerging role of GSNOR in oxidative stress regulation. Trends Plant Sci. https://doi.org/10.1016/j.tplants.2020.09.004 (2020).

71. Clark, D., Durner, J., Navarre, D. A. \& Klessig, D. F. Nitric oxide inhibition of tobacco catalase and ascorbate peroxidase. Mol. Plant Microbe Interact. 13 1380-1384 (2000)

72. Radi, R. Nitric oxide, oxidants, and protein tyrosine nitration. Proc. Natl Acad. Sci. USA 101, 4003-4008 (2004).

73. Chaki, M. et al. Tyrosine nitration provokes inhibition of sunflower carbonic anhydrase ( $\beta-C A)$ activity under high temperature stress. Nitric Oxide 29 30-33 (2013).

74. Tanou, G. et al. Oxidative and nitrosative-based signaling and associated post-translational modifications orchestrate the acclimation of citrus plants to salinity stress. Plant J. 72, 585-599 (2012).

75. Leterrier, $\mathrm{M}$. et al. Arsenic triggers the nitric oxide (NO) and Snitrosoglutathione (GSNO) metabolism in Arabidopsis. Environ. Pollut. 166, 136-143 (2012).

76. Souza, J. M. et al. Proteolytic degradation of tyrosine nitrated proteins. Arch. Biochem. Biophys. 380, 360-366 (2000).

77. Mata-Pérez, C. et al. Nitro-fatty acids in plant signaling: new key mediators of nitric oxide metabolism. Redox Biol. 11, 554-561 (2017).

78. Sánchez-Calvo, B., Barroso, J. B. \& Corpas, F. J. Hypothesis: nitro-fatty acids play a role in plant metabolism. Plant Sci. 199, 1-6 (2013).

79. Mata-Pérez, C. et al. Nitro-fatty acids in plant signaling: nitro-linolenic acid induces the molecular chaperone network in Arabidopsis. Plant Physiol. 170 686-701 (2016). 
80. Di Palma, A. A. et al. Nitro-oleic acid triggers ROS production via NADPH oxidase activation in plants: A pharmacological approach. J. Plant Physiol. 246, 153128 (2020)

81. Sun, $C$. et al. Aluminum induces distinct changes in the metabolism of reactive oxygen and nitrogen species in the roots of two wheat genotypes with different aluminum resistance. J. Agric. Food Chem. 65, 9419-9427 (2017).

82. Umbreen, S. et al. Specificity in nitric oxide signalling. J. Exp. Bot. 69, 3439-3448 (2018).

83. Spadaro, D. et al. The redox switch: dynamic regulation of protein function by cysteine modifications. Physiol. Plant. 138, 360-371 (2010).

84. Kim, S. O. et al. OxyR: a molecular code for redox-related signaling. Cell 109 383-396 (2002).

85. Kneeshaw, S., Gelineau, S., Tada, Y., Loake, G. J. \& Spoel, S. H. Selective protein denitrosylation activity of thioredoxin-h5 modulates plant immunity. Mol. Cell 56, 153-162 (2014)

86. Lee, U., Wie, C., Fernandez, B. O., Feelisch, M. \& Vierling, E. Modulation of nitrosative stress by $S$-nitrosoglutathione reductase is critical for thermotolerance and plant growth in Arabidopsis. Plant Cell 20, 786-802 (2008).

87. Kapuganti, J. G. et al. Regulating the regulator: nitric oxide control of posttranslational modifications. New Phytol. 227, 1319-1325 (2020).

88. Kohli, S. K. et al. Assessment of subcellular ROS and NO metabolism in higher plants: multifunctional signaling molecules. Antioxidants 8, 641 (2019).

89. Delledonne, M., Zeier, J., Marocco, A. \& Lamb, C. Signal interactions between nitric oxide and reactive oxygen intermediates in the plant hypersensitive disease resistance response. Proc. Natl Acad. Sci. USA 98, 13454-13459 (2001).

90. Ren, Y. et al. Nitric oxide alleviates salt stress in seed germination and early seedling growth of pakchoi (Brassica chinensis L.) by enhancing physiological and biochemical parameters. Ecotoxicol. Environ. Saf. 187, 109785 (2020).

91. Beligni, M. V. \& Lamattina, L. Nitric oxide stimulates seed germination and deetiolation, and inhibits hypocotyl elongation, three light-inducible responses in plants. Planta 210, 215-221 (2000).

92. Lanteri, M. L., Laxalt, A. M. \& Lamattina, L. Nitric oxide triggers phosphatidic acid accumulation via phospholipase D during auxin-induced adventitious root formation in cucumber. Plant Physiol. 147, 188-198 (2008).

93. Kwon, E. et al. AtGSNOR1 function is required for multiple developmental programs in Arabidopsis. Planta 236, 887-900 (2012).

94. Gong, B. et al. Unravelling GSNOR-mediated S-Nitrosylation and multiple developmental programs in tomato plants. Plant Cell Physiol. 60, 2523-2537 (2019).

95. Hussain, A. et al. Novel and conserved functions of S-nitrosoglutathione reductase in tomato. J. Exp. Bot. 70, 4877-4886 (2019).

96. Hendricks, S. \& Taylorson, R. Promotion of seed germination by nitrate, nitrite, hydroxylamine, and ammonium salts. Plant Physiol. 54, 304-309 (1974).

97. Hendricks, S. \& Taylorson, R. Promotion of seed germination by nitrates and cyanides. Nature 237, 169-170 (1972).

98. Piterková, J. et al. Nitric oxide is involved in light-specific responses of tomato during germination under normal and osmotic stress conditions. Ann. Bot. 110, 767-776 (2012).

99. Govindaraj, M., Masilamani, P., Albert, V. A. \& Bhaskaran, M. Plant derived smoke stimulation for seed germination and enhancement of crop growth: a review. Agric. Rev. 37, 87-100 (2016).

100. Gniazdowska, A., Krasuska, U., Dębska, K., Andryka, P. \& Bogatek, R. The beneficial effect of small toxic molecules on dormancy alleviation and germination of apple embryos is due to NO formation. Planta 232, 999-1005 (2010)

101. Lombardi, L., Mariotti, L., Picciarelli, P., Ceccarelli, N. \& Lorenzi, R. Ethylene produced by the endosperm is involved in the regulation of nucellus programmed cell death in Sechium edule Sw. Plant Sci. 187, 31-38 (2012).

102. Fan, H. F., Du, C. X. Ding, L. \& Xu, Y. L. Effects of nitric oxide on the germination of cucumber seeds and antioxidant enzymes under salinity stress. Acta Physiol. Plant. 35, 2707-2719 (2013).

103. Arc, E., Galland, M., Godin, B., Cueff, G. \& Rajjou, L. Nitric oxide implication in the control of seed dormancy and germination. Front. Plant Sci. 4, 346 (2013).

104. Liu, Y. et al. Nitric oxide-induced rapid decrease of abscisic acid concentration is required in breaking seed dormancy in Arabidopsis. New Phytol. 183 1030-1042 (2009).

105. $\mathrm{Xu}, \mathrm{H}$. et al. A molecular signal integration network underpinning Arabidopsis seed germination. Curr. Biol. 30, 3703-3712.e4 (2020).

106. Garcia-Mata, C. \& Lamattina, L. Nitric oxide and abscisic acid cross talk in guard cells. Plant Physiol. 128, 790-792 (2002).
107. Liu, J. et al. Nitric oxide affects seed oil accumulation and fatty acid composition through protein S-nitrosation. J. Exp. Bot. https://doi.org/10.1093/jxb/ eraa456 (2020)

108. Pagnussat, G. C., Simontacchi, M., Puntarulo, S. \& Lamattina, L. Nitric oxide is required for root organogenesis. Plant Physiol. 129, 954-956 (2002).

109. Sun, C. et al. Melatonin: a master regulator of plant development and stress responses. J. Integr. Plant Biol. 63, 126-145 (2020).

110. Pagnussat, G. C., Lanteri, M. L., Lombardo, M. C. \& Lamattina, L. Nitric oxide mediates the indole acetic acid induction activation of a mitogen-activated protein kinase cascade involved in adventitious root development. Plant Physiol. 135, 279-286 (2004).

111. Correa-Aragunde, N., Graziano, M., Chevalier, C. \& Lamattina, L. Nitric oxide modulates the expression of cell cycle regulatory genes during lateral root formation in tomato. J. Exp. Bot. 57, 581-588 (2006).

112. Piacentini, D. et al. Nitric oxide cooperates with auxin to mitigate the alterations in the root system caused by cadmium and arsenic. Front Plant Sci. 11, 1182 (2020).

113. Creus, C. M. et al. Nitric oxide is involved in the Azospirillum brasilense-induced lateral root formation in tomato. Planta 221, 297-303 (2005).

114. Guo, K. Xia, K. \& Yang, Z. M. Regulation of tomato lateral root development by carbon monoxide and involvement in auxin and nitric oxide. J. Exp. Bot 59, 3443-3452 (2008).

115. Wang, $\mathrm{H}$. et al. Nitric oxide enhances development of lateral roots in tomato (Solanum lycopersicum L.) under elevated carbon dioxide. Planta 237, 137-144 (2013).

116. Lombardo, M. C. Graziano, M. Polacco, J. C. \& Lamattina, L. Nitric oxide functions as a positive regulator of root hair development. Plant Signal. Behav. 1, 28-33 (2006).

117. Lombardo, M. C. \& Lamattina, L. Abscisic acid and nitric oxide modulate cytoskeleton organization, root hair growth and ectopic hair formation in Arabidopsis. Nitric Oxide 80, 89-97 (2018).

118. Fernández-Marcos, M., Sanz, L., Lewis, D. R., Muday, G. K. \& Lorenzo, O. Nitric oxide causes root apical meristem defects and growth inhibition while reducing PIN-FORMED 1 (PIN1)-dependent acropetal auxin transport. Proc. Natl Acad. Sci. USA 108, 18506-18511 (2011).

119. Yuan, H. M. \& Huang, X. Inhibition of root meristem growth by cadmium involves nitric oxide-mediated repression of auxin accumulation and signalling in Arabidopsis. Plant Cell Environ. 39, 120-135 (2016).

120. Graziano, M., Beligni, M. V. \& Lamattina, L. Nitric oxide improves internal iron availability in plants. Plant Physiol. 130, 1852-1859 (2002).

121. Graziano, M. \& Lamattina, L. Nitric oxide and iron in plants: an emerging and converging story. Trends Plant Sci. 10, 4-8 (2005).

122. Jin, C. W., Du, S. T., Shamsi, I. H., Luo, B. F. \& Lin, X. Y. NO synthase-generated NO acts downstream of auxin in regulating Fe-deficiency-induced root branching that enhances Fe-deficiency tolerance in tomato plants. J. Exp. Bot. 62, 3875-3884 (2011).

123. García, M. J. et al. A new model involving ethylene, nitric oxide and Fe to explain the regulation of Fe-acquisition genes in Strategy I plants. Plant Physiol. Biochem. 49, 537-544 (2011).

124. Fei, D. et al. Exogenous nitric oxide alleviated the inhibition of photosynthesis and antioxidant enzyme activities in iron-deficient Chinese cabbage (Brassica chinensis L.). Agric. Sci. China 7, 168-179 (2008).

125. Zhai, L. et al. Nitric oxide signaling is involved in the response to iron deficiency in the woody plant Malus xiaojinensis. Plant Physiol. Biochem. 109 515-524 (2016).

126. Zhu, X. F., Wang, B., Song, W. F., Zheng, S. J. \& Shen, R. F. Putrescine alleviates iron deficiency via NO-dependent reutilization of root cell-wall Fe in Arabidopsis. Plant Physiol. 170, 558-567 (2016).

127. Ye, Y. Q. et al. Elevation of NO production increases Fe immobilization in the Fe-deficiency roots apoplast by decreasing pectin methylation of cell wall. Sci. Rep. 5, 1-13 (2015).

128. Frungillo, L., Skelly, M. J., Loake, G. J., Spoel, S. H. \& Salgado, I. S-nitrosothiols regulate nitric oxide production and storage in plants through the nitrogen assimilation pathway. Nat. Commun. 5, 1-10 (2014)

129. Trevisan, S., Manoli, A. \& Quaggiotti, S. NO signaling is a key component of the root growth response to nitrate in Zea mays L. Plant Signal. Behav. $\mathbf{9}$ e28290 (2014)

130. Sun, $\mathrm{H}$. et al. Nitric oxide generated by nitrate reductase increases nitrogen uptake capacity by inducing lateral root formation and inorganic nitrogen uptake under partial nitrate nutrition in rice. J. Exp. Bot. 66, 2449-2459 (2015). 
131. Manoli, A. et al. NO homeostasis is a key regulator of early nitrate perception and root elongation in maize. J. Exp. Bot. 65, 185-200 (2014).

132. Jin, C. W., Du, S. T., Zhang, Y. S., Lin, X. Y. \& Tang, C. X. J. Differential regulatory role of nitric oxide in mediating nitrate reductase activity in roots of tomato (Solanum lycocarpum). Ann. Bot. 104, 9-17 (2009).

133. Du, S. et al. Regulation of nitrate reductase by nitric oxide in Chinese cabbage pakchoi (Brassica chinensis L.). Plant Cell Environ. 31, 195-204 (2008).

134. Hichri, I. et al. Nitric oxide: a multifaceted regulator of the nitrogen-fixing symbiosis. J. Exp. Bot. 66, 2877-2887 (2015).

135. Meilhoc, E., Boscari, A., Bruand, C., Puppo, A. \& Brouquisse, R. Nitric oxide in legume-rhizobium symbiosis. Plant Sci. 181, 573-581 (2011).

136. Wang, B. et al. Nitric oxide is involved in phosphorus deficiency-induced cluster-root development and citrate exudation in white lupin. New Phytol. 187, 1112-1123 (2010).

137. Zhu, X. F., Zhu, C. Q., Wang, C., Dong, X. Y. \& Shen, R. F. Nitric oxide acts upstream of ethylene in cell wall phosphorus reutilization in phosphorusdeficient rice. J. Exp. Bot. 68, 753-760 (2017).

138. Chen, Z. H. et al. Nitrate reductase mutation alters potassium nutrition as well as nitric oxide-mediated control of guard cell ion channels in Arabidopsis. New Phytol. 209, 1456-1469 (2016).

139. Xia, J. et al. Nitric oxide negatively regulates AKT1-mediated potassium uptake through modulating vitamin B6 homeostasis in Arabidopsis. Proc. Natl Acad. Sci. USA 111, 16196-16201 (2014).

140. Jamali, B., Eshghi, S. \& Tafazoli, E. Mineral composition of 'Selva'strawberry as affected by time of application of nitric oxide under saline conditions. Hortic. Environ. Biotechnol. 56, 273-279 (2015).

141. Farag, M. et al. Nitric oxide protects carbon assimilation process of watermelon from boron-induced oxidative injury. Plant Physiol. Biochem. 111, 166-173 (2017).

142. Liu, S. et al. Beneficial behavior of nitric oxide in copper-treated medicinal plants. J. Hazard. Mater. 314, 140-154 (2016).

143. Zhang, Y., Han, X., Chen, X., Jin, H. \& Cui, X. Exogenous nitric oxide on antioxidative system and ATPase activities from tomato seedlings under copper stress. Sci. Hortic. 123, 217-223 (2009).

144. Jeyakumar, P. \& Balamohan, T. Micronutrients for horticultural crops. Training manual on role of balanced fertilization for horticultural crops, TNAU, Coimbatore-03. (2007).

145. Liu, M. et al. Ethylene and nitric oxide interact to regulate the magnesium deficiency-induced root hair development in Arabidopsis. New Phytol. 213, 1242-1256 (2017).

146. Nabi, R. B. S. et al. Nitric oxide regulates plant responses to drought, salinity, and heavy metal stress. Environ. Exp. Bot. 161, 120-133 (2019).

147. Tailor, A., Tandon, R. \& Bhatla, S. C. Nitric oxide modulates polyamine homeostasis in sunflower seedling cotyledons under salt stress. Plant Signal. Behav. 14, 1667730 (2019).

148. Shi, Q., Ding, F., Wang, X. \& Wei, M. Exogenous nitric oxide protect cucumber roots against oxidative stress induced by salt stress. Plant Physiol. Biochem. 45 , 542-550 (2007).

149. Valderrama, R. et al. Nitrosative stress in plants. FEBS Lett. 581, 453-461 (2007).

150. David, A., Yadav, S., Baluška, F. \& Bhatla, S. C. Nitric oxide accumulation and protein tyrosine nitration as a rapid and long distance signalling response to salt stress in sunflower seedlings. Nitric Oxide 50, 28-37 (2015)

151. Tanou, G. et al. Proteomics reveals the overlapping roles of hydrogen peroxide and nitric oxide in the acclimation of citrus plants to salinity. Plant J. $\mathbf{6 0}$, 795-804 (2009).

152. Liao, W. B., Huang, G. B., Yu, J. H. \& Zhang, M. L. Nitric oxide and hydrogen peroxide alleviate drought stress in marigold explants and promote its adventitious root development. Plant Physiol. Biochem. 58, 6-15 (2012)

153. Silveira, N. M. et al. Evidence towards the involvement of nitric oxide in drought tolerance of sugarcane. Plant Physiol. Biochem. 115, 354-359 (2017)

154. Arasimowicz-Jelonek, M., Floryszak-Wieczorek, J. \& Kubis, J. Involvement of nitric oxide in water stress-induced responses of cucumber roots. Plant Sci. 177, 682-690 (2009).

155. Nasibi, F. \& Kalantari, K. M. Influence of nitric oxide in protection of tomato seedling against oxidative stress induced by osmotic stress. Acta Physiol. Plant. 31, 1037-1044 (2009).

156. Kaya, C., Ashraf, M., Wijaya, L. \& Ahmad, P. The putative role of endogenous nitric oxide in brassinosteroid-induced antioxidant defence system in pepper (Capsicum annuum L.) plants under water stress. Plant Physiol. Biochem. 143, 119-128 (2019).
157. García-Mata, C. \& Lamattina, L. Nitric oxide induces stomatal closure and enhances the adaptive plant responses against drought stress. Plant Physiol. 126, 1196-1204 (2001)

158. Fan, $H$. et al. Effects of exogenous nitric oxide on antioxidation and DNA methylation of Dendrobium huoshanense grown under drought stress. Plant Cell Tissue Organ Cult. 109, 307-314 (2012).

159. Puyaubert, J. \& Baudouin, E. New clues for a cold case: nitric oxide response to low temperature. Plant Cell Environ. 37, 2623-2630 (2014).

160. Ziogas, V. et al. Nitrosative responses in citrus plants exposed to six abiotic stress conditions. Plant Physiol. Biochem. 68, 118-126 (2013).

161. Sehrawat, A. \& Deswal, R. S-nitrosylation analysis in Brassica juncea apoplast highlights the importance of nitric oxide in cold-stress signaling. J. Proteome Res. 13, 2599-2619 (2014).

162. Parankusam, S., Adimulam, S. S., Bhatnagar-Mathur, P. \& Sharma, K. K. Nitric oxide (NO) in plant heat stress tolerance: current knowledge and perspectives. Front. Plant Sci. 8, 1582 (2017).

163. Corpas, F. J., del Río, L. A. \& Barroso, J. B. Post-translational modifications mediated by reactive nitrogen species: nitrosative stress responses or components of signal transduction pathways? Plant Signal. Behav. 3, 301-303 (2008).

164. Corpas, F. J. et al. Nitric oxide imbalance provokes a nitrosative response in plants under abiotic stress. Plant Sci. 181, 604-611 (2011).

165. Manrique-Gil, I., Sánchez-Vicente, I., Torres-Quezada, I., \& Lorenzo, O. Nitric oxide function during oxygen deprivation in physiological and stress processes. J. Exp. Bot. https://doi.org/10.1093/jxb/eraa442 (2020).

166. Huang, J., Yang, M. \& Zhang, X. The function of small RNAs in plant biotic stress response. J. Integr. Plant Biol. 58, 312-327 (2016).

167. Hamann, T. Plant cell wall integrity maintenance as an essential component of biotic stress response mechanisms. Front. Plant Sci. 3, 77 (2012).

168. Qi, J. et al. Reactive oxygen species signaling and stomatal movement in plant responses to drought stress and pathogen attack. J. Integr. Plant Biol. 60, 805-826 (2018).

169. Scheler, C., Durner, J. \& Astier, J. Nitric oxide and reactive oxygen species in plant biotic interactions. Curr. Opin. Plant Biol. 16, 534-539 (2013).

170. Lazalt, A., Beligni, M. V. \& Lamattina, L. J. Nitric oxide preserves the level of chlorophyll in potato leaves infected by Phytophthora infestans. Eur. J Plant Pathol. 103, 643-651 (1997).

171. Lam, E., Kato, N. \& Lawton, M. Programmed cell death, mitochondria and the plant hypersensitive response. Nitric Oxide 411, 848-853 (2001).

172. Ma, W., Smigel, A., Tsai, Y. C., Braam, J. \& Berkowitz, G. A. Innate immunity signaling: cytosolic $\mathrm{Ca}^{2+}$ elevation is linked to downstream nitric oxide generation through the action of calmodulin or a calmodulin-like protein. Plant Physiol. 148, 818-828 (2008)

173. Zaninotto, F., La Camera, S., Polverari, A. \& Delledonne, M. Cross talk between reactive nitrogen and oxygen species during the hypersensitive disease resistance response. Plant Physiol. 141, 379-383 (2006).

174. Tada, Y. et al. Nitric oxide and reactive oxygen species do not elicit hypersensitive cell death but induce apoptosis in the adjacent cells during the defense response of oat. Mol. Plant Microbe Interact. 17, 245-253 (2004).

175. Floryszak-Wieczorek, J., Arasimowicz, M., Milczarek, G., Jelen, H. \& Jackowiak, H. Only an early nitric oxide burst and the following wave of secondary nitric oxide generation enhanced effective defence responses of pelargonium to a necrotrophic pathogen. New Phytol. 175, 718-730 (2007).

176. Glazener, J. A., Orlandi, E. W. \& Baker, C. J. The active oxygen response of cell suspensions to incompatible bacteria is not sufficient to cause hypersensitive cell death. Plant Physiol. 110, 759-763 (1996).

177. Zhang, C., Czymmek, K. J. \& Shapiro, A. D. Nitric oxide does not trigger early programmed cell death events but may contribute to cell-to-cell signaling governing progression of the Arabidopsis hypersensitive response. Mol. Plant Microbe Interact. 16, 962-972 (2003).

178. León, J., Castillo, M. C., Coego, A., Lozano-Juste, J. \& Mir, R. Diverse functional interactions between nitric oxide and abscisic acid in plant development and responses to stress. J. Exp. Bot. 65, 907-921 (2014).

179. Chaki, M. et al. Involvement of reactive nitrogen and oxygen species (RNS and ROS) in sunflower-mildew interaction. Plant Cell Physiol. 50, 265-279 (2009).

180. Liu, J. Z. et al. S-Nitrosylation inhibits the kinase activity of tomato phosphoinositide-dependent kinase 1 (PDK1). J. Biol. Chem. 292, 19743-19751 (2017).

181. Iyer, A. K. V., Rojanasakul, Y. \& Azad, N. Nitrosothiol signaling and protein nitrosation in cell death. Nitric Oxide 42, 9-18 (2014). 
182. Wang, Y. Q. et al. S-nitrosylation of AtSABP3 antagonizes the expression of plant immunity. J. Biol. Chem. 284, 2131-2137 (2009).

183. Lindermayr, C., Sell, S., Müller, B., Leister, D. \& Durner, J. Redox regulation of the NPR1-TGA1 system of Arabidopsis thaliana by nitric oxide. Plant Cell 22, 2894-2907 (2010).

184. Cui, B. et al. S-nitrosylation of the zinc finger protein SRG1 regulates plant immunity. Nat. Commun. 9, 1-12 (2018).

185. Palma, J. M., Freschi, L., Rodríguez-Ruiz, M., González-Gordo, S. \& Corpas, F. J. Nitric oxide in the physiology and quality of fleshy fruits. J. Exp. Bot. 70, 4405-4417 (2019).

186. González-Gordo, S., Rodríguez-Ruiz, M., Palma, J. M. \& Corpas, F. J. Superoxide radical metabolism in sweet pepper (Capsicum annuum L.) fruits is regulated by ripening and by a NO-enriched environment. Front. Plant Sci. 11, 485 (2020).

187. Wills, R., Ku, V. \& Leshem, Y. Fumigation with nitric oxide to extend the postharvest life of strawberries. Postharvest Biol. Technol. 18, 75-79 (2000).

188. Bowyer, M., Wills, R., Badiyan, D. \& Ku, V. Extending the postharvest life of carnations with nitric oxide-comparison of fumigation and in vivo delivery. Postharvest Biol. Technol. 30, 281-286 (2003).

189. Saadatian, M., Ahmadiyan, S., Akbari, M. \& Balouchi, Z. Effects of pretreatment with nitric oxide on kiwifrut storage at low temperature. Adv. Environ. Biol. 6 , 1902-1909 (2012).

190. Dong, J., Zhang, M., Lu, L., Sun, L. \& Xu, M. Nitric oxide fumigation stimulates flavonoid and phenolic accumulation and enhances antioxidant activity of mushroom. Food Chem. 135, 1220-1225 (2012).

191. Pristijono, P., Golding, J. \& Wills, R. Use of nitric oxide to reduce surface browning of fresh cut lettuce and apple slices. In International Conference on Quality Management of Fresh Cut Produce 746 (Eds Kanlayanarat, S. et al.) 237-244 (2007). https://doi.org/10.17660/ActaHortic.2007.746.26.

192. Yang, X. \& Liu, Y. B. Residual analysis of nitric oxide fumigation on fresh fruit and vegetables. Postharvest Biol. Technol. 132, 105-108 (2017).

193. Yang, X. \& Liu, Y. B. Nitric oxide fumigation for control of spotted wing Drosophila (Diptera: Drosophilidae) in strawberries. J. Econ. Entomol. 111, 1180-1184 (2018).

194. Walse, S. S., Jimenez, L. R., Hall, W. A., Tebbets, J. S. \& Obenland, D. M. Optimizing postharvest methyl bromide treatments to control spotted wing drosophila, Drosophila suzukii, in sweet cherries from Western USA. J. Asia Pac. Entomol. 19, 223-232 (2016).

195. Liu, Y. B. Nitric oxide fumigation for control of western flower thrips and its safety to postharvest quality of fresh fruit and vegetables. J. Asia Pac. Entomol. 19, 1191-1195 (2016)

196. Yang, X. \& Liu, Y. B. Nitric oxide fumigation for postharvest pest control on lettuce. Pest Manag. Sci. 75, 390-395 (2019).
197. Liu, Y. B., Yang, X. \& Simmons, G. Efficacy of nitric oxide fumigation for controlling codling moth in apples. Insects 7, 71 (2016).

198. Pristijono, P., Wills, R. \& Golding, J. Inhibition of browning on the surface of apple slices by short term exposure to nitric oxide (NO) gas. Postharvest Biol. Technol. 42, 256-259 (2006).

199. Wills, R., Pristijono, P. \& Golding, J. Browning on the surface of cut lettuce slices inhibited by short term exposure to nitric oxide (NO). Food Chem. 107, 1387-1392 (2008).

200. Lai, T., Chen, Y., Li, B., Qin, G. \& Tian, S. Mechanism of Penicillium expansum in response to exogenous nitric oxide based on proteomics analysis. J. Proteomics 103, 47-56 (2014).

201. $\mathrm{Hu}, \mathrm{M}$. et al. Inhibition on anthracnose and induction of defense response by nitric oxide in pitaya fruit. Sci. Hortic. 245, 224-230 (2019).

202. Zheng, $Y$. et al. Preharvest $L$-arginine treatment induced postharvest disease resistance to Botrysis cinerea in tomato fruits. J. Agric. Food Chem. 59, 6543-6549 (2011).

203. Liao, W. B., Zhang, M. L. \& Yu, J. H. Role of nitric oxide in delaying senescence of cut rose flowers and its interaction with ethylene. Sci. Hortic. 155, 30-38 (2013).

204. Zeng, C., Liu, L. \& Xu, G. The physiological responses of carnation cut flowers to exogenous nitric oxide. Sci Hortic. 127, 424-430 (2011).

205. Singh, H., Singh, N., Singh, A., Hussain, I. \& Yadav, V. Physiological and biochemical roles of nitric oxide against toxicity produced by glyphosate herbicide in Pisum sativum. Russ. J. Plant Physiol. 64, 518-524 (2017).

206. Beligni, M. A. V. \& Lamattina, L. Nitric oxide protects against cellular damage produced by methylviologen herbicides in potato plants. Nitric Oxide $\mathbf{3}$, 199-208 (1999).

207. Hung, K. T., Chang, C. J. \& Kao, C. H. Paraquat toxicity is reduced by nitric oxide in rice leaves. Plant Physiol. 159, 159-166 (2002).

208. Ferreira, L. C. et al. Nitric oxide reduces oxidative stress generated by lactofen in soybean plants. Pestic. Biochem. Physiol. 97, 47-54 (2010).

209. Keyster, M. et al. Nitric oxide increases the enzymatic activity of three ascorbate peroxidase isoforms in soybean root nodules. Plant Signal. Behav. 6, 956-961 (2011).

210. Sun, $\mathrm{C}$. et al. Nitric oxide alleviates aluminum-induced oxidative damage through regulating the ascorbate-glutathione cycle in roots of wheat. $J$. Integr. Plant Biol. 57, 550-561 (2015).

211. Yin, Y. L. et al. Interplay between mitogen-activated protein kinase and nitric oxide in brassinosteroid-induced pesticide metabolism in Solanum lycopersicum. J. Hazard. Mater. 316, 221-231 (2016).

212. Oliveira, H. C., Gomes, B. C., Pelegrino, M. T. \& Seabra, A. B. Nitric oxidereleasing chitosan nanoparticles alleviate the effects of salt stress in maize plants. Nitric Oxide 61, 10-19 (2016). 